Published in final edited form as:

Adv Healthc Mater. 2015 November 18; 4(16): 2530-2556. doi:10.1002/adhm.201400781.

\title{
Fabricated elastin
}

Giselle C. Yeo ${ }^{1,2}$, Behnaz Aghaei-Ghareh-Bolagh ${ }^{\# 1,2}$, Edwin P. Brackenreg" ${ }^{\# 1,2}$, Matti A. Hiob $^{\# 1,2}$, Pearl Lee ${ }^{\# 1,2}$, and Anthony S. Weiss ${ }^{1,2,3,{ }^{*}}$

${ }^{1}$ Charles Perkins Centre, The University of Sydney, NSW 2006, Australia

2 School of Molecular Bioscience, The University of Sydney, NSW 2006, Australia

${ }^{3}$ Bosch Institute, The University of Sydney, NSW 2006, Australia

\# These authors contributed equally to this work.

\section{Abstract}

The mechanical stability, elasticity, inherent bioactivity, and self-assembly properties of elastin make it a highly attractive candidate for the fabrication of versatile biomaterials. The ability to engineer specific peptide sequences derived from elastin allows for precise control of these physicochemical and organizational characteristics, and further broadens the diversity of elastinbased applications. Elastin and elastin-like peptides can also be modified or blended with other natural or synthetic moieties, including peptides, proteins, polysaccharides and polymers, to augment existing capabilities or confer additional architectural and biofunctional features to compositionally pure materials. Elastin and elastin-based composites have been subjected to diverse fabrication processes, including heating, electrospinning, wet spinning, solvent casting, freeze-drying, and cross-linking, for the manufacture of particles, fibers, gels, tubes, sheets and films. The resulting materials can be tailored to possess specific strength, elasticity, morphology, topography, porosity, wettability, surface charge and bioactivity. This extraordinary tunability of elastin-based constructs enables their use in a range of biomedical and tissue engineering applications such as targeted drug delivery, cell encapsulation, vascular repair, nerve regeneration, wound healing, and dermal, cartilage, bone and dental replacement.

\section{Keywords}

Tropoelastin; elastin; elastin-like peptide; fabrication; tissue engineering; biomaterials

\section{Introduction}

\subsection{Structural and biological properties of elastin}

Elastin is a polymeric extracellular matrix protein consisting of cross-linked tropoelastin monomers organized around a fibrillin-rich microfibrillar structure ${ }^{[1]}$. In vivo, elastin forms part of the elastic fibers that provide elastic properties to tissues such as arteries, ligaments

\footnotetext{
* Corresponding author: Tel: +61293513464; Fax: +61293515858; tony.weiss@ sydney.edu.au; Postal address: Level 4, Charles Perkins Centre D17, The University of Sydney, NSW 2006, Australia.
} 
and lungs. These elastic fibers display incredible resilience and structural stability, with aortic isolates of elastin exhibiting a half-life of $\sim 70$ years ${ }^{[2]}$.

The principal component of elastin is tropoelastin, which consists of mostly non-polar amino acids arranged in alternating hydrophobic and hydrophilic domains. Within the hydrophobic domains are repeating sequence motifs, which confer elasticity to the protein and contribute to cell signalling ${ }^{[3]}$. The hydrophilic domains consist mainly of lysine-rich stretches involved in cross-linking. This cross-linking process is facilitated in vivo by lysyl oxidase, which converts lysine residues to form allysine aldol, lysinonorleucine, desmosine and isodesmosine bonds with surrounding modified and unmodified lysine residues ${ }^{[4]}$, conferring functionally important stability to the protein array.

Tropoelastin, as a biologically active molecule, has a number of cell-interactive sites $[5,6]$ that direct numerous signalling events through glycosaminoglycans (GAGs) ${ }^{[7]}$, the elastin binding protein (EBP) ${ }^{[8]}$, and integrins ${ }^{[9]}$, Tropoelastin interactions with EBP primarily occur via the hydrophobic VGVAPG motif. In contrast, integrin contacts have been characterised at the tropoelastin C-terminus, which terminates with an RKRK recognition site for the integrin $\alpha_{v} \beta_{3}{ }^{[5]}$. Additional interactions also transpire at an upstream tropoelastin site for integrin $\alpha_{v} \beta_{5}{ }^{[6,10]}$. Tropoelastin not only mediates cellular processes such as cytoskeletal organization, chemotaxis, proliferation, and differentiation, but also mediates the local tissue environment through the regulation of matrix proteases ${ }^{[11]}$.

\subsection{Organizational ability of elastin}

Tropoelastin exhibits the ability to self-assemble into higher-order structures. Coacervation is a highly ordered process that aligns specific lysine residues between tropoelastin monomers through the entropic association of hydrophobic regions ${ }^{[12]}$. In an aqueous solution, the hydrophobic domains are surrounded by clathrate water, whose thermodynamic stability is altered internally by protein concentration, and externally by solution temperature, $\mathrm{pH}$, and ionic strength ${ }^{[13]}$. A temperature increase at physiological salt concentration is most commonly used to decrease clathrate order and reveal the hydrophobic domains for tropoelastin association ${ }^{[14]}$. The alignment of lysines within the elastin assemblies is critical for cross-linking. In the absence of coacervation, tropoelastin monomers fail to cross-link, despite the appropriate oxidative modifications to lysine residues ${ }^{[15]}$.

The importance of the tropoelastin self-assembly to functional elastic fiber formation is reflected in elastic fiber pathologies such as ductus arteriosus ${ }^{[16]}$, congenital supravalvular aortic stenosis (SVAS) ${ }^{[17]}$ and cutis laxa ${ }^{[18]}$, all of which feature alterations to the tropoelastin primary structure that disrupt intermolecular coacervation and crosslinking, and result in impaired fiber assembly ${ }^{[19]}$.

\subsection{Use and derivation for applications}

The structural stability, elastic resilience, and bioactivity of tropoelastin, combined with its capacity for self-assembly, make this protein a highly desirable candidate for the fabrication of biomaterials. In addition, its dominant presence in a number of native tissues, accompanied by inefficient replacement during injury, drives its use as biomimetic scaffolds. 
Such scaffolds would not only reflect the physical features of the extracellular matrix, but would also possess biological cues for target cell incorporation and signaling for extracellular matrix remodeling in tissue engineering applications. The ability to distill important structural, biological and self-assembly properties of tropoelastin within short, chemically synthesizable peptide derivatives has further broadened the development and applications of elastin-based materials. These elastin-like peptides (ELPs) are predominantly based on repetitive hydrophobic sequences in tropoelastin, most commonly the VPGXG motif, where $X$ represents any amino acid except proline ${ }^{[20]}$. This review explores the primary fabrication methods, properties and applications of elastin-based constructs, and focuses on materials that are synthesized solely from tropoelastin or ELPs, or integrated with other proteins, peptides, polymers or compounds that confer additional structural and functional benefits for specific purposes.

\section{Elastin-only constructs}

This section addresses the fabrication techniques and biological applications of materials that are constructed predominantly from elastin, either in the form of the tropoelastin monomer, or hydrolyzed elastic fibers. The elastin can be pre-modified to facilitate immediate cross-link formation, or post-processed with the addition of cross-linking agents.

\subsection{Elastin production}

The ability of tropoelastin to self-assemble has driven investigations into utilizing coacervation to facilitate the fabrication of elastin-based materials such as hydrogels and electrospun scaffolds for tissue repair. However, obtaining pure tropoelastin/elastin in large quantities has historically been a major challenge. Elastin isolation can be achieved by a number of methods, resulting in a range of end products. Solubilization with hot alkali, guanidine, or more recently, oxalic acid (produces a-elastin) and potassium hydroxide (produces $\kappa$-elastin) treatment can be used to hydrolyze elastic fibers components harvested from animal tissues [21]. Tissues such as ligamentum nuchae or large arterial vessels are preferred, as their high elastin content improves yields and reduces contaminant proteins ${ }^{[22]}$. Solubilized elastin retains many physiochemical properties of tropoelastin, including the ability to self-assemble ${ }^{[7]}$. However, these methodologies do not give rise to intact tropoelastin monomers and often consist of heterogeneous products due to their harsh nature ${ }^{[23]}$. In addition, the reliance on animal tissues limits large-scale production and carries additional ethical and moral implications.

The introduction of recombinant technology to produce synthetic tropoelastin addresses these concerns, by providing scalable host overexpression systems to meet the demands of industrial applications. In the development of these systems, gene optimization is critically important. This was exemplified by poor yields in early implementations of an Escherichia coli overexpression system, due to rare bacterial codons populating up to $35 \%$ of the native human tropoelastin gene ${ }^{[24]}$. By engineering a synthetic gene highly-optimized for bacterial expression, significantly enhanced protein yields of multi-gram quantities are obtained for biomaterial fabrication ${ }^{[25]}$. 


\subsection{Elastin-only fibrous scaffolds}

2.2.1 Fabrication-Electrospinning is a robust process that allows for the construction of nano-to-micro diameter fibers from both synthetic polymers and natural proteins. As fiber size is decreased, the surface-to-volume ratio increases, offering more sites for cellular interaction ${ }^{[26]}$. When designed to match the mechanical and signaling properties of the native tissue environment, electrospun materials can improve and accelerate healing in a variety of clinical applications ${ }^{[27]}$.

A typical electrospinning apparatus used to produce elastin-based scaffolds requires at least three components: a high voltage supply, a flow-controlled syringe needle, and a conductive collecting target that is typically grounded ${ }^{[28]}$ (Figure 1). The collecting target geometry is most commonly manipulated to produce desired structures, such as sheets and tubes of varying dimensions. Parallel collectors have also successfully produced aligned parallel fibers that have important cellular and mechanical implications as subsequently discussed ${ }^{[29]}$.

Tropoelastin solutions are prepared by dissolving in a volatile solvent such as 1,1,1,3,3,3hexafluoro-2-propanol (HFP) and loaded into a syringe ${ }^{[30]}$. A high direct current voltage in the order of $20 \mathrm{kV}$ is applied to the syringe needle to create an electric field that produces a polymer jet at a predetermined flow rate ${ }^{[31]}$. At the needle tip, an electric charge is conveyed to the contacting solution, inducing a mutual charge repulsion force in the opposite direction to the surface tension. This force reshapes the solution into a conical shape (Taylor cone) ${ }^{[32]}$. At the tip, there is sufficient charge repulsion to overcome the surface tension, and the solution is expelled as a jet towards the grounded target. As it travels towards the target, the solvent evaporates and the polymer fiber is deposited to form a nascent scaffold [33]. Elastin scaffolds may subsequently be treated with cross-linkers (commonly chemicals such as glutaraldehyde or hexamethylene diisocyanate (HMDI) to improve stability and insolubility ${ }^{[34]}$. Variations in cross-linking efficiency have been observed depending on the cross-linker used, however, this can easily be compensated for by adjusting the length of incubation periods. Upon cross-linking, elastin scaffolds are highly stable, maintaining structural integrity beyond 180 days under physiological conditions ${ }^{[35]}$.

2.2.2 Properties and applications-Electrospun elastin fibers exhibit a characteristic thin ribbon-like morphology, ranging from $0.9-5.5 \mu \mathrm{m}$ for tropoelastin and 0.6-3.6 $\mu \mathrm{m}$ for a-elastin ${ }^{[36]}$ (Table 1). Fiber width is strongly dependent on flow rate and concentration. Continuous fibers are produced in $20 \%$ (w/v) solutions ${ }^{[37]}$. When concentrations are lowered to $15 \%(\mathrm{w} / \mathrm{v})$ and below, fibers become discontinuous and gain the appearance of bead-like structures throughout the scaffold. The characteristic ribbon morphology is maintained independent of fiber alignment, which can be altered from a wavy whip-like appearance to parallel fibers via adjustments to the collecting target. Post-processing of scaffolds with cross-linkers has a modest effect on fiber width due to hydration [38], but gross fiber morphology is maintained even after extended cross-linking.

Due to the intrinsic stability of tropoelastin, its secondary structure and biological activity are preserved after the electrospinning process ${ }^{[35]}$. In contrast, electrospun collagen becomes denatured and suffers from degradation ${ }^{[39]}$. Remarkably, even uncross-linked 
tropoelastin scaffolds show no evidence of degradation, and when re-dissolved retain their ability to coacervate and promote cell growth ${ }^{[35]}$.

Electrospun tropoelastin scaffolds are highly elastic, with a Young's modulus of $265 \mathrm{kPa}$, comparable to that of natural elastin which ranges from $100-350 \mathrm{kPa}{ }^{[40]}$. By aligning the fibers within the scaffold, elasticity can be increased to deliver a Young's modulus of 111 $\mathrm{kPa}$, while preserving ultimate stress $(116 \mathrm{kPa})$ and strain characteristics $(\sim 1.5 \%)^{[29]}$.

A broad range of cell types have demonstrated positive growth and spreading on electrospun tropoelastin scaffolds, such as dermal fibroblasts, and vascular endothelial and smooth muscle cells. Cell attachment occurs within 30 minutes post-seeding ${ }^{[41]}$. After 14 days, extracellular matrix remodeling by the adherent cells is apparent, with the deposition of matrix proteins such as collagen and fibronectin to mimic their native environment. The scaffolds support extended cell growth to at least 35 days post-seeding ${ }^{[41]}$. For cell types or applications where cellular orientation is important for function, elastin scaffolds have been demonstrated to direct cell growth in an organized manner parallel to aligned fibers, while maintaining native cell morphology [29].

Achieving cellular infiltration requires scaffolds with sufficiently large porosity. In dermal replacements, pore sizes of at least $11 \mathrm{um}$ were required to achieve fibroblast penetration into the material ${ }^{[41]}$. In conditions that produced smaller average pore sizes $(\sim 7 \mathrm{um})$, cell proliferation was restricted to the surface of the scaffold. Scaffold porosity is typically modulated by increasing the solution flow rate. Scaffold structures produced at high flow rates $(3-5 \mathrm{~mL} / \mathrm{h})$ support cell penetration ${ }^{[42]}$. Inversely, scaffolds benefit mechanically from lower flow rates $(1 \mathrm{~mL} / \mathrm{h})$, displaying a higher tensile strength while maintaining a similar elastic modulus. Flow rates of $5 \mathrm{~mL} / \mathrm{h}$ represent a critical point, where any further increase in flow rate, and consequent increases in average fiber diameter and scaffold porosity, substantially decreases material density and structurally limits its potential usefulness ${ }^{[38]}$.

The biocompatibility of tropoelastin scaffolds engineered with high porosity has been assessed in subcutaneous murine models ${ }^{[41]}$. Six-week-old implants demonstrate multilayer encapsulation by fibroblast cells and moderate scaffold remodeling and degradation. The main contributors to scaffold degradation are infiltrating fibroblast cells that reconstruct the local environment by depositing native extracellular matrix proteins such as collagen fibers. Immunogenic factors including neutrophils and monocytes are not observed, which indicates that the scaffolds are well-tolerated by the host.

Tropoelastin scaffolds have also found use as a stem cell delivery vehicle, as they mechanically and biologically reflect a native ECM which is important in regulating stem cell differentiation. Scaffolds laden with adipose-derived stem cells are non-immunogenic, increase the rate of wound closure, and enhance wound healing in vivo ${ }^{[27]}$.

Electrospun scaffolds also serve as a viable treatment alternative to allogenic and xenogenic skin grafts for the $>6$ million severe burns injuries occurring worldwide each year ${ }^{[43]}$. While acceptable for short-term use, foreign skin grafts have limited availability, are strongly rejected by the host immune system, and possess elevated infection risks ${ }^{[44]}$. Elastin-based scaffolds are therefore appealing as they mimic the dermal environment and avoid the 
cytotoxic leaching common in synthetic polymers such as poly(lactide-co-glycolide) and poly( $\varepsilon$-caprolactone) ${ }^{[45]}$. Additionally, they offer advantages over similar ECM-like scaffolds formed from collagen, which contract and lead to reduced patient mobility ${ }^{[46]}$.

\subsection{Elastin-only hydrogels}

2.3.1 General fabrication-Hydrogels are a class of highly absorbent materials consisting of a cross-linked polymer structure. Elastin hydrogels are typically cast by crosslinking tropoelastin solutions under physiological conditions. In the initial stages of this process, tropoelastin monomers reversibly self-organize into spherical nanoparticles ${ }^{[13]}$. By altering the concentration of tropoelastin, the size of these nanoparticles can be modulated up to a maximum of $\sim 200 \mathrm{~nm}$. Upon the addition of cross-linkers, these spheres coalesce to form interconnected beaded networks with distinct concentration-defined morphologies. Hydrogels formed at high tropoelastin concentrations $(30-40 \mathrm{mg} / \mathrm{mL})$ have a porous structure, and possess fiber diameters resembling those of in vivo elastic fibers ${ }^{[47]}$.

Hydrogel cross-linking can be achieved through numerous enzymatic, chemical and irradiation methods. The degree of cross-linking is influenced by the concentration of the cross-linking agent and the duration of incubation ${ }^{[48]}$. The most commonly used crosslinkers for elastin-based hydrogels are chemical reagents such as glutaraldehyde, bis(sulfosuccinimidyl) suberate (BS3), and HMDI [49]. Each exhibits varying cross-linking efficiencies that dictate the cross-linking density, and hence, the structural properties of the resulting material. Elastin hydrogels formed with glutaraldehyde exhibit lower mechanical strength compared to constructs produced with HMDI, as glutaraldehyde limits crosslinking to lysine residues which represent under $1 \%$ of the tropoelastin sequence ${ }^{[50]}$. HMDI-crosslinked hydrogels are more mechanically robust, due to increased cross-link formation involving additional cysteine and histidine residues.

The degree and nature of a hydrogel's porosity largely dictate its function and potential applications. Hydrogels designed with high porosity and interconnectivity to allow nutrient and oxygen exchange are attractive candidates for tissue regeneration applications. Strategies to engineer porosity into hydrogels include phase inversion, use of organic solvents, or foaming with dense gases ${ }^{[51]}$. Such methods introduce pores into the hydrogel structure by thermodynamically-driven phase separation, which divides the solution into polymer-rich and polymer-deficient phases. During processing, the polymer-deficient phase is removed, and the remaining polymer-rich phase solidifies. The manner and kinetics by which this occurs influences the final physical form of the hydrogel ${ }^{[52]}$.

2.3.2 General properties and applications-Tropoelastin hydrogels are highly elastic, exhibiting a Young's Modulus of 220-280 kPa, compared with 300-600 kPa for hydrogels made from solubilized elastin ${ }^{[48]}$. Both a-elastin and tropoelastin hydrogels display a uniquely linear stress/strain relationship when extended, far exceeding all other known biologically-derived materials ${ }^{[53]}$. Stress/strain measurements to gauge elasticity reveal a linear relationship up to about $60 \%$ strain for a-elastin and $150 \%$ for tropoelastin [48]. Material stiffness is dictated largely by porosity, and as such, can be readily controlled. For example, a-elastin hydrogels destined for orthopedic applications have been produced with 
compressive moduli closely matched to the $5.4 \mathrm{kPa}$ compressive modulus of intervertebral discs ${ }^{[54]}$.

Comparisons between hydrogels synthesized from tropoelastin and solubilized elastin are complicated by the differential use of cross-linkers, casting conditions, and rehydration conditions (Table 2). At $4{ }^{\circ} \mathrm{C}$, tropoelastin hydrogels absorb $63 \pm 5 \mathrm{~g} \mathrm{H}_{2} \mathrm{O} / \mathrm{g}$ protein. This absorptive ability is reduced to around half $\left(33 \pm 4 \mathrm{~g} \mathrm{H}_{2} \mathrm{O} / \mathrm{g}\right.$ protein) upon a temperature increase to $37{ }^{\circ} \mathrm{C}$. The addition of ionic salts further reduces swelling, with physiological $\mathrm{NaCl}$ concentrations resulting in over 10 -fold reduction at both temperatures ${ }^{[48]}$.

The overarching cellular response to tropoelastin hydrogels is attrractive. A wide range of cell types including fibroblasts, endothelial cells, epithelial cells, embryonic kidney and fibrosarcoma cells of both human and animals origin remain adherent and adopt proliferative states following seeding on these hydrogels ${ }^{[50]}$. Differential cell migratory responses are seen on the hydrogel surfaces, characterized by pervasive cell infiltration on the more porous top surface, and cell monolayer formation on the casting surface. Implantation of the hydrogels in the dorsum of guinea pigs to assess immunogenic response has demonstrated that tropoelastin hydrogels are innocuous and invoke only a mild foreign-body response comparable to collagen ${ }^{[48]}$.

2.3.3 Hydrogels formed with high pressure carbon dioxide-While cross-linkers are necessary to achieve adequate mechanical integrity of elastin hydrogels, they also result in small pore sizes with insufficient interconnecting channels for nutrient exchange and cell infiltration. A popular strategy to overcome this issue is to incorporate high pressure ( 60 bar) dense gases such as $\mathrm{CO}_{2}$ during the casting process. This facilitates coacervation through interactions with hydrophobic tropoelastin domains and accelerates cross-linking within the polymer-rich phase ${ }^{[55]}$. The changes in pressure and coacervation kinetics alter hydrogel porosity. At atmospheric pressure, thick-walled pores are produced with limited interconnectivity. When synthesized at high pressure, a more rigid material is achieved that contains pores with a 10 -fold reduction in wall thickness. Additionally, cross-linking at high pressure results in the formation of micro-channels and a uniformly porous structure within the hydrogel. In contrast, gels fabricated at atmospheric conditions display non-uniform porosity underneath the solid surface layers. Due to this structural augmentation, the mechanical properties of the hydrogel are also altered, as exemplified by a 1.5 -fold increase in elastic modulus ${ }^{[50]}$.

When seeded with fibroblasts, elastin gels formed at high pressure enhance cellular infiltration throughout the material, primarily due to the presence of large channels. In contrast, hydrogels formed at atmospheric conditions are limited by their solid surfaces, which allow cells to form a confluent monolayer but tends to prevent them from extending into the material ${ }^{[56]}$.

2.3.4 Hydrogels formed from tropoelastin and solubilized elastin-Hybrid gels formed from combining tropoelastin with a-elastin gain mechanical strength when a 50/50 ratio or higher of tropoelastin is used ${ }^{[42]}$. When characterized across a range of mechanical metrics, hybrid gels outperform single-constituent gels in key areas of compressive strength 
and energy loss. The compressive modulus of hybrid hydrogels is elevated over 6-fold compared to that of a-elastin gels ${ }^{[50]}$. Their ability to support cell growth, being largely dictated by porosity, is analogous to single-constituent gels. As in tropoelastin-only constructs, fibroblasts can be allowed to infiltrate hybrid gels by synthesizing them in high pressure $\mathrm{CO}_{2}$ order to enhance porosity ${ }^{[50]}$.

2.3.5 Hydrogels formed from modified tropoelastin-The modification of tropoelastin residues is an emerging strategy to accelerate coacervation and allow for rapid, chemical-free cross-linking. Gel formation occurs within a short time frame (under a minute), which is multiple orders of magnitude faster than the typical requisite $24 \mathrm{hr}$ incubation period. Cytotoxicity concerns are also addressed by removing the use of toxic cross-linkers and organic solvents from the process ${ }^{[57]}$. The manufactured elastin-based gels also benefit from enhanced stability and minimal leaching in vivo. Importantly, this fabrication process is cytocompatible, allowing for three-dimensional cellular encapsulation throughout the hydrogel structure.

The most explored methodology of tropoelastin modification is the reaction of tropoelastin lysine residues with methacrylic anhydride ${ }^{[58]}$. This process has a minimal effect on the protein as a whole, as illustrated by the maintenance of tropoelastin secondary structure in response to varying degrees of methacrylation. This process has been shown to increase tropoelastin hydrophobicity, thus enhancing the rate of coacervation. Gel properties are largely dictated by the degree of methacrylation ${ }^{[42]}$. Highly-methacrylated monomers increase the density of crosslinking, and consequently reduce the hydrogel pore size and swelling ratio. When compared to unmodified a-elastin hydrogels, the swelling ratio of methacrylated tropoelastin (MeTro) gels is reduced $~ 1.5$ fold depending on casting conditions. The elastic benefit of constructing hydrogels from MeTro is consistently demonstrated, with a dramatically higher elastic modulus of up to 100-fold over similarly processed biological materials ${ }^{[59]}$. Additionally, MeTro gels experience low energy losses in response to deformation and show up to $400 \%$ extensibility, indicative of a high elastic resilience that is $\sim 3$ fold higher than that of native tropoelastin.

Cellular growth is actively promoted on the surface of MeTro gels, at far higher levels compared to hydrogels made from synthetic polymers such as polyethylene glycol (PEG), which suffer from poor cellular adhesion and growth ${ }^{[58]}$. The ability of MeTro gels to sustain an expansive array of cell types likely indicates that the cell-interactive regions of tropoelastin are presented in an active conformation on the material surface. The capacity of these fabricated gels to effectively conduct nutrient exchange throughout the gel structure has also been demonstrated. Cells embedded within the 3D hydrogel structure during casting remain viable for at least 7 days ${ }^{[58]}$. This technology represents a major breakthrough for elastin-based hydrogels and has potential applications as cell-laden constructs.

\section{Composite elastin-based materials}

Elastin can be synthesized in conjunction with other proteins or polymers to augment the structural and functional properties of a range of biomaterials. 


\subsection{Composite elastin-based fibrous scaffolds}

As with pure-elastin materials, electrospinning of composite elastin-based constructs gives rise to a non-woven, nanofibrous, 3D structure with high specific surface area, high porosity, and high pore interconnectivity ${ }^{[33,60,61]}$. This technique allows for the fabrication of engineered scaffolds mimicking the structure and architecture of the native extracellular matrix ${ }^{[33,60]}$. Electrospinning has been widely used for the fabrication of tubular and flat scaffolds with random or aligned fiber orientation for skin, bone, nerve, and particularly, vascular tissue applications (Table 3) ${ }^{[30,60,62-68] .}$

Electrospun materials made entirely from natural polymers such as elastin or collagen have the advantage of being more biocompatible and less immunogenic, due to their inherent capacity for cell interactions ${ }^{[69]}$. However, they often lack the requisite mechanical properties for tissue replacement scaffolds ${ }^{[60]}$. For example, although collagen is a dominant component in many tissues, its use in biomaterial design is limited due to inadequate post-processing mechanical strength, compounded by rapid degradation and loss of structural integrity in vivo ${ }^{[70,71]}$. On the other hand, electrospun constructs based on pure synthetic polymers such as poly ( $\varepsilon$-caprolactone) (PCL), poly(lactic-co-glycolic acid) (PLGA), poly(lactic acid) (PLA), poly (L-lactic acid) (PLLA), poly(L-lactide-co- $\varepsilon$ caprolactone) PLCL, and polydioxanone (PDO) exhibit superior mechanical properties and biodegradation kinetics ${ }^{[72]}$. However, although they can mimic the physical dimension and structure of the native ECM, they lack cell recognition sites necessary for biological signaling. Furthermore, the typically hydrophobic nature of these scaffolds adversely affects cell attachment and activity ${ }^{[70]}$.

To overcome these problems, current strategies co-electrospin elastin with natural proteins or synthetic polymers [26, 63-66, 68, 73-77]. Fabrication of these hybrid materials is a simple and cost-effective process, which involves the physical blending of individual components at different ratios prior to electrospinning into nanofibrous materials with novel, complementary, and tunable mechanical properties $[65,66,70,74]$. The composite tropoelastin solutions often display more favourable viscosity and electrospinning efficiency ${ }^{[67,68]}$. The electrospun elastin-based hybrid scaffolds also better mimic the architecture and components of native tissue, and display improved strength, structural integrity, elasticity, and wettability $[26,63,66,68,74,76-78]$. Moreover, they show increased bioactivity including cell attachment ${ }^{[30,63,66,73,74]}$, proliferation ${ }^{[30,68,73,74]}$, maturation ${ }^{[63,68]}$, migration ${ }^{[67]}$, and infiltration $[64,66,67,74,76]$ compared to biologically inert synthetic scaffolds.

Co-electrospun tropoelastin-based blends have been developed as vascular grafts. Composite solutions were loaded in a syringe pump and electrospun onto a rotating mandrel under a high voltage power supply to produce a cylindrical structure ${ }^{[64-67,74,76]}$. Tubular electrospun scaffolds have been manufactured from elastin mixed with collagen [67, 79, 80], elastin with PDO [76], elastin with gelatin and PLGA ${ }^{[37,66,74]}$, elastin with collagen and PLGA ${ }^{[65,68]}$ or other synthetic polymers like PLLA, PLCL ${ }^{[65]}$ and PCL $[64,65,81]$.

An ideal biomimetic vascular graft should not only resemble the composition and structure of native vessels, but should also possess sufficient mechanical integrity to withstand the high pressure, pulsatile environment of the blood stream ${ }^{[79]}$. To address this need, 
multilayered vascular grafts have been developed. One such construct is a cell-laden, trilayer vascular graft composed of collagen type I and tropoelastin ${ }^{[79]}$. It is characterized by an electrospun, cross-linked outer tube with 20:80 tropoelastin:collagen ratio, and an inner tube with 70:30 tropoelastin:collagen. Fibroblasts are seeded on the external surface, smooth muscle cells between the tube layers, and smooth muscle cells and endothelial cells within the innermost lumen. Another bilayer vascular conduit consists of sequentially electrospun tropoelastin and PCL. First, tropoelastin solution is delivered on the mandrill to generate the inner luminal layer, then a hybrid solution of tropoelastin:PCL (80:20) is deposited atop and cross-linked with glutaraldehyde vapor ${ }^{[30]}$. In other studies, tri-layer grafts have been constructed, in which the intima comprises only elastin and PCL, the media comprised elastin, collagen and PCL, and the adventitia comprised only collagen and PCL. These scaffolds are cross-linked with either 1-ethyl-3-(3-dimethylaminopropyl)-carbodiimide (EDC) and $70 \%$ ethanol or genipin [64, 77]. Other multi-layered constructs have likewise been formed by sequential electrospinning of elastin, gelatin and polyglyconate blends [60], or elastin, gelatin, poliglecaprone (PGC) and PCL ${ }^{[73]}$. This process enables the tuning of each layer to fit various structural and compositional requirements. Electrospun elastinbased composite vascular conduits have increased elasticity and burst strength to reduce the compliance mismatch between the graft and the native vasculature ${ }^{[64,68,73]}$. The elastin component, on the other hand, improves biocompatibility and decreases the risk of thrombosis $[30,65,66]$.

Aside from vascular repair, electrospun elastin-based composite scaffolds can serve other tissue engineering applications. Combinations of elastin with PCL have been reported for peripheral nerve regeneration. Neural cells attach and elongate in the direction of aligned nanofibers within the material ${ }^{[63]}$. Blended collagen and elastin mats have been studied as potential dermal substitutes for wound healing ${ }^{[67]}$. An elastin, gelatin and PLGA composite scaffold has been investigated for replacement of soft tissues such as heart, lung and blood vessels ${ }^{[37]}$.

\subsection{Composite elastin-based hydrogels}

To fabricate elastin-based porous scaffolds (hydrogels) with desirable properties for tissue engineering, various methods including gas foaming and freeze-drying have been employed (Figure 2) ${ }^{[82-87]}$.

Gas foaming utilizes a foaming agent added to a viscous polymer solution to generate inert gas inside the solution. The expansion of dispersed gas within the solution, followed by sudden gas release, results in porous structures ${ }^{[88-90]}$. This has been demonstrated by the fabrication of a highly porous hydrogel composed of elastin and PCL. PCL and $\mathrm{NaCl}$ particles were mixed by melt mixing and gas-foamed using carbon dioxide at 65 bar and $70{ }^{\circ} \mathrm{C}$. The PCL scaffolds were then impregnated with an elastin solution containing glutaraldehyde, at atmospheric pressure, in vacuum, or at high pressure $\mathrm{CO}_{2}[88,89,91]$.

Freeze-drying is another technique for the fabrication of highly porous elastin-based composite scaffolds ${ }^{[82-87]}$. Freezing a dispersion or solution results in the formation of ice crystals, which are subsequently removed by freeze-drying to leave pores inside the material. Pore size is inversely related to the freezing rate ${ }^{[82]}$. To illustrate, a tropoelastin- 
collagen solution frozen at $-80^{\circ} \mathrm{C}$ and freeze-dried produces porous disc-shaped ${ }^{[86]}$ or tubular scaffolds ${ }^{[87]}$. Likewise, an elastin-glycosaminoglycan-collagen composite hydrogel has been manufactured by gelation at $37^{\circ} \mathrm{C}$, followed by lyophilization and cross-linking with 1-ethyl-3-(3 dimethylaminopropyl)carbodiimide/N-hydroxysuccinimide (EDC/ NHS) ${ }^{[85]}$. Similarly, silk-elastin hydrogels have been made by freeze-drying genipin-crosslinked samples, and further stabilizing them via methanol immersion ${ }^{[84]}$. Tubular porous scaffolds are constructed by dipping a mandrill in protein solution and freeze-drying. Repeated solution coating and freeze-dry cycles allow build-up into multi-layered constructs, such as that produced with an outer collagen film and an inner tropoelastincollagen sheet ${ }^{[87]}$.

As previously discussed, elastin-based hybrid materials have excellent ECM-mimetic properties $[83,87,89,91]$. Structurally, composite hydrogels allow greater tailoring of mechanical properties for diverse applications (Table 4 ) $[83,84,86,89,91]$. The elastin component confers elasticity to the composite scaffolds ${ }^{[83]}$, and hence decreases the energy loss and hysteresis of the constructs ${ }^{[89,91]}$. This permits the scaffolds to withstand high burst pressures ${ }^{[87]}$ and extreme deformation under compressive load ${ }^{[85,86]}$. Moreover, the addition of elastin induces large pore formation ${ }^{[84,86]}$, which enhances cell growth and infiltration within the scaffolds ${ }^{[84-86,91]}$. Elastin also imparts hydrophilicity to composite scaffolds, and thus improves their wettability and water uptake $[83,84,89,91]$.

Porous elastin-based composite hydrogels have been utilized in various applications. Tropoelastin and collagen composites have been developed for small-diameter blood vessels ${ }^{[86]}$. Collagen-elastin-GAG constructs haven been investigated for nucleus pulposus regeneration ${ }^{[85]}$, or as mimetic scaffolds for skin and cartilage ${ }^{[83]}$. Silk-tropoelastin scaffolds have also been eyed as wound dressings and drug release vehicles ${ }^{[84]}$, and elastinPCL composites as cartilage replacement ${ }^{[89,91]}$.

\subsection{Composite elastin-based cast materials}

Casting is another method used for the construction of elastin-based composite materials ${ }^{[75,92-96]}$. In this process, a solution is poured into a mold or on a substrate and allowed to solidify, such as by air drying. This technique has been employed to cast a porous membrane composed of alginate, elastin and PEG on a glass petri dish, followed by crosslinking using $\mathrm{CaCl}_{2} /$ carbodiimide ${ }^{[75]}$. Elastic patches have also been prepared in a similar manner using a combination of elastin, hyaluronan and silk. The components were mixed with the BS3 cross-linker and immediately casted into polydimethylsiloxane (PDMS) molds at $37^{\circ} \mathrm{C}$ to facilitate elastin-driven coacervation and cross-linking ${ }^{[92]}$. Silk-elastin films have similarly been prepared by casting the blended solution on a PDMS substrate, and physically cross-linking the resulting material with water vapour under vacuum at $60^{\circ} \mathrm{C}$, or with thermal treatment such as autoclaving ${ }^{[93-96] .}$

These tropoelastin-silk composite films have tuneable surface charge ${ }^{[94]}$ and roughness ${ }^{[93,95]}$ based on the ratio of individual components, which greatly impact material functionality. By modulating surface charge, the growth of charge-sensitive cell/tissue networks such as neural cells can be defined ${ }^{[94]}$. Scaffolds can be tailored with low surface 
roughness and high stiffness to promote the proliferation and myogenic differentiation of C2C12 myoblasts $[93,96]$.

\section{Elastin-like peptide (ELP) constructs}

ELPs are artificial biopolymers which contain elastin-based repeat motifs, commonly the pentapeptide sequence Val-Pro-Gly-Xaa-Gly (VPGXG), where the guest residue Xaa can be any naturally occurring amino acid except for proline ${ }^{[97]}$. Other elastin-based motifs used in the design of ELPs are the nonapeptide LGAGGAGVL ${ }^{[98]}$ and pentapeptides KGGVG ${ }^{[99]}$, GVGVP ${ }^{[100]}$, VGGVG ${ }^{[101]}$. Another well-characterized ELP consists of repeats of the VPVXG motif derived from bovine tropoelastin. More recently, in an attempt to enhance the properties of the polypeptide, human elastin-like polypeptides (HELPs) have been synthesized based on the VAPGVG motif, the most highly-recurring sequence in the human tropoelastin homolog ${ }^{[102]}$.

\subsection{Synthesis of ELPs}

Genetically encoded synthesis of ELPs in an heterologous host, most commonly bacteria or eukaryotic cells, allows precise control over the sequence, molecular weight, and hence stereochemistry of the polypeptides ${ }^{[103,104]}$. These variables are often difficult to control in chemical polymerization processes ${ }^{[105]}$. ELPs are readily produced from biological expression systems at relatively high yields, and conveniently purified via inverse temperature cycling without the need for chromatography ${ }^{[106]}$

Historically, ELP synthesis involved the generation of a library of oligomeric genes by concatemerization, or random unidirectional ligation of a monomer gene ${ }^{[107]}$. However, this method does not allow control over the number or order of repeat units, resulting in heterogeneous oligomer populations of different lengths ${ }^{[107,108]}$.

An alternative approach, termed overlap extension polymerase chain reaction (OEPCR ${ }^{[109]}$, uses short DNA oligonucleotides that simultaneously serve as primer and template to yield various repetitive DNA chain lengths. To overcome the low specificity of this method, a modified technique was applied, termed overlap extension rolling circle amplification. This approach combines rolling circle amplification with OEPCR ${ }^{[110]}$. It involves a single PCR-type reaction that utilizes circular single-stranded DNA to produce linear repeats of the gene, followed by thermally-cycled overlap extension to generate highfidelity and high-yield repetitive gene libraries. The synthesis of such extensive gene libraries has enabled the investigation of previously unidentified ELP polymers.

Another method of ELP synthesis is recursive directional ligation (RDL), which utilizes stepwise oligomerization of a DNA monomer encoding a short ELP oligomer of 5-10 pentapeptides. The monomer DNA contains restriction endonuclease recognition sequences for isolation of the DNA insert from the parent vector ${ }^{[103]}$. The number of repetitive sequences is increased until a specified target is reached. This process enables the production of large block copolymers with customized sequence, mass and orientation [111]. However, only particular sequences are compatible with this method of synthesis, as the 
endonuclease restriction sites overlap with the coding region. Additionally, cloning efficiency is limited by incomplete vector digestion or self-ligation events $[112,113]$.

To address the limitations of the RDL technology, a significantly improved cloning methodology called recursive directional ligation by plasmid reconstruction was utilized [113]. This method ligates two segments of a parent plasmid, each containing a copy of the desired oligomer, to reconstitute a functional plasmid. The ligation step utilizes type II restriction endonucleases, which are compatible with any oligonucleotide sequence.

Furthermore, cloning efficiency is improved as a functional plasmid is produced only after successful ligation.

Most ELP applications require large quantities of the polypeptide at high purity and at competitive economic cost, which can be addressed by recombinant expression systems such as $E$. coli ${ }^{[114]}$. Yields of up to $400 \mathrm{mg} / \mathrm{L}$ culture have been obtained from $E$. coli expression systems, for either free ELPs or chimeric constructs ${ }^{[115]}$. However, obtaining such yields requires the optimization of many factors, such as the addition of exogenous proline and alanine, amino acids that are disproportionately abundant in ELPs $[115,116]$. Endotoxins are difficult to remove from the final ELP product [117], so an alternative recombinant expression system based on Pichia pastoris as a host organism has been explored. Expressed ELPs are secreted by yeast cells and can be purified directly from the culture medium [118] Yeast-based expression systems also have the ability to be incorporated into industrial-scale fermentation processes. However, product yields obtained from yeast systems, at approximately $255 \mathrm{mg} / \mathrm{L}$ culture, are often lower than those from bacterial systems ${ }^{[118,119]}$. Plant-based systems are increasingly being recognized as an efficient and inexpensive means of ELP production ${ }^{[120]}$, but this is not yet optimized for maximum yield and purification efficiency [121]. Column chromatography is a standard method for the purification of expressed ELPs but lower cost alternatives have been explored ${ }^{[122]}$. A common strategy, inverse transition cycling (ITC) exploits the reversible inverse temperature transition property of ELPs. This technique typically involves several rounds of sequential steps which include heating, centrifugation, cooling, and solubilization ${ }^{[106,123]}$. As increasing the temperature allow the aggregation of ELPs, forming a coacervate, centrifugation will then allow the pellet to be separated from the supernatant that may contain soluble contaminants and other compounds. Resolubilization in a cooler environment, then repeating the sequence of heating and centrifugation allow further purification ${ }^{[124]}$. Conveniently, this property is retained even after the ELP is grafted to other polypeptide or protein components, allowing the purification of a diverse range of ELP fusion proteins ${ }^{[106,122]}$.

\subsection{Tunable properties of ELPs}

The genetic engineering of ELPs allows precise control over their composition, sequence, and molecular weight, which, in turn, determine the physicochemical properties of resulting constructs ${ }^{[103]}$. ELPs are widely used in bioapplications due to their responsiveness to stimuli, monodispersity, biocompatibility, and established biodegradation profile [125].

ELPs are thermally responsive and undergo a reversible inverse temperature phase transition ${ }^{[126]}$. An increase in temperature above a characteristic transition temperature $\left(\mathrm{T}_{t}\right)$ induces the hydrophobic self-association of ELP molecules to form a highly viscous 
coacervate ${ }^{[127]}$. Below the $\mathrm{T}_{t}$, the polymer chains are hydrated by clathrate water and the ELPs remain soluble in aqueous solution ${ }^{[128]}$. However, above the $\mathrm{T}_{t}$, the clathrate water structures become disorganized [129], allowing hydrophobic assembly of polymer chains into ordered and dynamic $\beta$-spirals ${ }^{[126]}$. The $\beta$-spirals then assemble to form filaments or other 3D structures as determined by the ELP sequence (Figure $3 \mathrm{~A}){ }^{[130]}$.

The phase transition temperature of ELPs is affected by the sequence, molecular mass, and concentration of the polypeptide, as well as the ionic strength and $\mathrm{pH}$ of the solution [131], allowing fine-tuning of the assembly process. The choice of guest residue within the ELP repeat motif influences the $\mathrm{T}_{t}$ (Figure $3 \mathrm{~B}$ ). An apolar guest residue increases the overall hydrophobicity of the polypeptide and therefore lowers its $\mathrm{T}_{t}$. Conversely, a polar guest residue increases $\mathrm{T}_{t}$. The correlation between $\mathrm{T}_{t}$ and ELP polarity has been demonstrated by the different phase transition behaviour of a V8X2 ELP with different guest residues. Increasing the ELP hydrophobicity by replacing Val with Ile, Leu, Phe, Tyr or Trp decreases $\mathrm{T}_{t}$. In contrast, decreasing hydrophobicity by replacing Val with Gln, Asn, Ser, Thr, Gly or Ala increases $T_{t}{ }^{[132]}$. Proline is not substituted as a guest residue because it disrupts the conformation of the molecule, which hinders the native folding and coacervation process [97]. The presence of lysine residues in ELPs confers an amphiphilic characteristic ${ }^{[133]}$ that allows the formation of stable micelle-like structures ${ }^{[134]}$.

Studies have shown that increasing the molecular weight without substantially changing overall hydropathy significantly lowers $\mathrm{T}_{t}{ }^{[135]}$. In addition, guest residues that contain groups susceptible to ionization allow the regulation of $\mathrm{T}_{t}$ via changes in solution $\mathrm{pH}^{[129]}$. The mechanical properties of ELPs can also be altered by replacing the glycine in the third position of the VPGXG repeat with alanine and an additional methyl group. The property of the ELP becomes plastic-like ${ }^{[136]}$. However, the first glycine cannot be replaced by any other amino acid apart from alanine, as it impedes $\beta$-turn formation during assembly ${ }^{[137]}$.

The biocompatibility of ELPs can be improved with the incorporation of sequence motifs for cell interactions ${ }^{[138,139]}$. ELPs designed to include an RGD based integrin ligand have been shown to restrict non-specific adsorption of proteins. Accordingly, polymer surfaces functionalized with such ELPs demonstrate a higher level of cell attachment and spreading, stronger cell binding affinity, and increased proliferation compared to random short peptides ${ }^{[140]}$ This tunable functionality has encouraged the use of ELPs in substrate modification strategies for enhanced cellular responses ${ }^{[138]}$.

\subsection{ELP hydrogels}

4.3.1 Fabrication-The tunable properties of ELPs are highly advantageous for the fabrication of diverse materials such as hydrogels, films and fibers [141]. ELP hydrogels, in particular, have drawn a lot of attention in the past decade due to their applications in drug delivery and tissue engineering ${ }^{[142]}$.

ELP hydrogels can be constructed from the physical polymerization of monomers in the absence of covalent bonds between the polypeptide moieties. This method is illustrated by the hydrophobic aggregation of ELP triblock copolymers designed with a central hydrophilic region and capped with hydrophobic residues at both ends ${ }^{[143]}$. The 
hydrophobic domains aggregate at temperatures above the ELP $\mathrm{T}_{t}$, creating a hydrogel that is stabilized by physical cross-links. Another method of physical polymerization involves ultrasonication of the ELP monomers to produce a hydrogel by physical chain entanglement ${ }^{[144]}$. This technique is beneficial for the encapsulation and preservation of bioactive molecules within the hydrogel structure. For example, drug-laden ELP hydrogels have been formed by the sonication of a $[\mathrm{VGVPG}]_{120}$ solution below the $\mathrm{T}_{t}$, followed by addition of drug molecules and gelation above $\mathrm{T}_{t}{ }^{[144]}$. Physical cross-linking has several advantages over chemical cross-linking approaches, including the simplicity of processing and the minimization of potential chemical toxicity. However, although the mechanical properties of physically cross-linked polymers can be tuned through the choice of solvent and the ELP sequence, they generally exhibit a lower strength matrix which may not be suitable for tissue engineering purposes ${ }^{[145]}$.

The strength and cohesion of ELP hydrogels can be greatly increased by chemical crosslinking to generate covalent bonds between ELP moieties to build a macroscopic networked matrix. Chemical cross-linking of ELPs is typically achieved via reactive residues such as lysine, glutamine or cysteine. ELP materials can be cross-linked by $\boldsymbol{\gamma}$-irradiation [146, 147], transglutaminase enzymes ${ }^{[148]}$, UV light ${ }^{[149]}$, or chemical cross-linking agents such as the amine-reactive compounds BS3, disuccinimidyl suberate (DSS), $\beta$ -

[tris(hydroxymethyl)phosphino]-propionic acid (THPP) or tris-succinimidyl aminotriacetate (TSAT) ${ }^{[150-153]}$. Separate teams led by McMillan ${ }^{[108,154]}$ and Trabbic-Carlson ${ }^{[153]}$ have generated ELP hydrogels using the amine-reactive reagents BS3 and TSAT, respectively. ELP blocks utilised for the construction of these hydrogels are often lysine-rich, such as the sequence $\left[(\mathrm{VPGVG})_{4}(\mathrm{VPGKG})\right]^{[108,154]}$ or $\left[(\mathrm{VPGKG})(\mathrm{VPGVG})_{\mathrm{n}}\right]^{153}$, in order to facilitate cross-linking. The ELP solutions are blended with these chemical cross-linkers and allowed to set into a hydrogel.

4.3.2 Properties-ELP hydrogels exhibit thermal responsiveness, which can be controlled by altering the constituent ELP. The use of an ELP component with charged residues enables the temperature transition properties of the resulting hydrogel to be modulated by $\mathrm{pH}$ and salt content. To illustrate, a standard VPGXG template with Ile as the guest residue produced a pH-insensitive material with a $\mathrm{T}_{t}$ of $34{ }^{\circ} \mathrm{C}[108,152]$. In contrast, the $\mathrm{T}_{t}$ of a material with a Lys guest residue shifted from $28^{\circ} \mathrm{C}$ in $0.1 \mathrm{M} \mathrm{NaOH}$ to $75^{\circ} \mathrm{C}$ in unbuffered water. The magnitude of this shift is suggestive of self-buffering by the lysine residues. Additionally, the lysine-substituted ELP construct did not coacervate below $100^{\circ} \mathrm{C}$ in a Tris-buffered solution, indicating inhibition of the aggregation process by the charged residues. The addition of salt $(150 \mathrm{mM} \mathrm{NaCl})$ to buffered or unbuffered solutions produced a uniform $\mathrm{T}_{t}$ of $50^{\circ} \mathrm{C}$, presumably due to the screening of electrostatic repulsion between charged lysines ${ }^{[155]}$. Following the same principle, the hydrogel $\mathrm{T}_{t}$ drops from $75^{\circ} \mathrm{C}$ to $35^{\circ} \mathrm{C}$ after cross-linking due to the conversion of amine groups to uncharged amides.

The correlation between ELP hydrogel fabrication temperature and temperature of transition impacts greatly on the structural properties of the material. Cross-linked hydrogels exhibit opalescence indicative of microsyneresis, which is a microscopic phase separation of the hydrophobic and hydrophilic moieties of the material ${ }^{[156]}$. To investigate the structural rearrangements that accompany this phase transition, ELP hydrogels cross-linked above and 
below the $\mathrm{T}_{t}$ were snap-frozen in liquid ethane. Electron microscopy studies revealed that gels formed below the $\mathrm{T}_{t}$ exhibit an interconnected network of dendritic leaflets, while those formed at high temperatures consist of beaded, worm-like filaments. These filaments aggregate into bundles resembling the structure of the native elastic fiber, consistent with the morphology reported for elastin-mimetic materials ${ }^{[157]}$. This structure is proposed to be the result of inherent elastin-based molecular self-organization which forms the basis of elastic function ${ }^{[108,152]}$.

ELP hydrogels also display variable temperature-dependent stiffness, ranging from 0.24-3.7 $\mathrm{kPa}$ at $7^{\circ} \mathrm{C}$ to $1.6-15 \mathrm{kPa}$ at $37^{\circ} \mathrm{C}$, depending on the primary structure of the ELP component ${ }^{[158]}$. At low temperatures, the gels are almost perfectly elastic with very little measurable phase shift. At higher temperatures, the gels lose water, which increases viscous loss. Loss angles vary from $\sim 1$ at $7^{\circ} \mathrm{C}$ to $5-15$ at $37^{\circ} \mathrm{C}$, with the greatest losses evident in gels with low ELP concentration, and in which the ELP component is of low molecular mass and has low lysine content (Figure 4). When strained at low temperatures (e.g. $7^{\circ} \mathrm{C}$ ), the functional crosslinks of the hydrogel bear the entire load. However, at higher temperatures where the ELP gels display a contracted structure, strain forces are transmitted not only through the cross-links but also through the closely-interacting ELP chains ${ }^{[153]}$.

Functionally, the extent of hydration displayed by ELP hydrogels can also be tailored according to the temperature response of the materials. In contrast to the rapid aggregation of ELP solutions at $\mathrm{T}_{t}$, cross-linked ELP hydrogels exhibit gradual changes in swelling behavior. ELP hydrogels can contract up to $90 \%$ of their volume, as the temperature is increased over a $50{ }^{\circ} \mathrm{C}$ range ${ }^{[153,159]}$, which likely reflects changes in the molecular morphology of the material with temperature.

Chemically cross-linked ELP hydrogels have shear and elastic moduli similar to that of native elastin and other connective tissues (Table 5). These features can be regulated by altering the type of cross-linker, as well as the concentration and molecular weight of the ELP monomer. Mechanical properties of ELP hydrogels can also be enhanced by reducing the propensity of ELP solutions for phase separation. One approach is the design of ELP triblock co-polymer polypeptides, composed of a central hydrophilic block with a $\mathrm{T}_{\mathrm{t}}$ above $37^{\circ} \mathrm{C}$ flanked by hydrophobic end-blocks with a $\mathrm{T}_{\mathrm{t}}$ below $37^{\circ} \mathrm{C}$. Gelation is promoted by the reduction in phase separation due to the bridging of the central blocks $[111,160]$.

\subsection{Applications of ELP constructs}

Regular elastin extracted from animal tissues are heterogeneous in mass, sequence and structural topology ${ }^{[161]}$. Materials derived from these products can therefore form structures that exhibit inconsistent and heterogeneous properties. Such products may also contain animal pathogens, immunogenic protein sequences, or harsh chemical residues ${ }^{[162]}$. While recombinant human tropoelastin addresses many of the problems associated with animalsourced elastins, it is relatively technically difficult and expensive to mass produce. Moreover, the size, structural complexity and inherent flexibility of tropoelastin makes it immensely difficult to accurately determine the chemical and physical processes that occur in materials fabricated from tropoelastin. Therefore, it can be challenging to apply rational engineering principles to design novel materials ${ }^{[12,162]}$. On the other hand, the relative ease 
of rationally designing ELP materials has resulted in a vast array of applications in biomedicine, such as drug delivery systems and tissue engineering technologies ${ }^{[153]}$ (Figure $6)$.

4.4.1 Local drug delivery-Injected small molecule drugs rapidly disperse throughout the body and are quickly cleared by kidney filtration, providing minimal therapeutic value $^{[163]}$. As a result, many drugs that have shown great promise in vitro fail to translate into useful therapies in vivo. To increase drug accumulation in the target tissue and reduce drug density in surrounding tissues, current drug delivery strategies work toward increasing circulation time, decreasing incidental metabolization, and targeting tissue-specific cell receptors or specific intracellular locales ${ }^{[164]}$. Such targeted drug delivery systems must have a high capacity for drug loading, show sustained, controllable drug release, exhibit efficient tissue infiltration, and be resistant to reticuloendothelial degradation ${ }^{[165]}$.

ELP constructs meet these criteria and are used as injectable drug depots $[166,167]$. Chemically, these constructs possess low viscosity during administration, and can polymerize within minutes of injection. ELP solutions have been shown to be capable of intramuscular in situ gelation, and the resulting hydrogel material exhibits long term retention ${ }^{[166,167]}$. In addition, ELP materials are non-cytotoxic and produce no toxic degradation products ${ }^{[168]}$. As an elastin mimetic, the ELP component is inherently biocompatible and biodegradable, and can be tuned to surpass the mechanical properties of naturally-derived polymers. Importantly, the inverse temperature transition of ELPs enables the entrapment of drug molecules within coacervate assemblies.

The ELP coacervates are able to maintain structural integrity when injected into parts of the body with low fluid flow, such as the intra-articular spaces of the synovial joints [169, 170]. Low concentrations of the bound drug are then released over a relatively long period as the ELP carriers slowly dissipate, allowing increased drug accumulation in target tissues ${ }^{[171]}$. To illustrate, the injection of an ELP-based anti-cytokine drug depot into rat spinal perineural tissue showed potential in the treatment of long-term sciatic pain ${ }^{[172]}$. The enzymatic degradation of ELP assemblies for drug release can be preferentially targeted to regions with increased elastase activity, which often correlate with pathological conditions such as pulmonary emphysema, cystic fibrosis, bacterial infections, inflammation, chronic wounds and atherosclerosis ${ }^{[173]}$. In support, a stable ELP hydrogel demonstrated enhanced drug release when exposed to elastolytic activity from Pseudomonas aeruginosa and from activated human polymorphonuclear leukocytes ${ }^{[174]}$.

The cross-linking of ELPs increases the range of its drug depot applications. As an example, ELP cross-linking has been shown to dramatically increase the viscosity of ELP-drug preparations. THPP-treated ELPs have a frequency independent dynamic viscosity of $\sim 0.37$ $\mathrm{Pa}$ s at $0.1 \mathrm{~Hz}$ in contrast to the $\sim 0.08 \mathrm{~Pa}$ s of uncross-linked ELPs ${ }^{[175]}$. This compares to the $\sim 1 \mathrm{~Pa}$ s dynamic viscosity of synovial fluid and indicates the suitability of the material for syringe and needle injection at room temperature. Drug release by cross-linked ELP constructs depends on the cross-linked structure as well as the properties of the drug molecule. An ELP hydrogel saturated with either cefazolin or vancomycin exhibited variable drug release dynamics under simulated physiological conditions ${ }^{[175]}$. The higher molecular 
weight cefazolin drug was released consistently with no initial burst release, and reached the minimum inhibitory concentration for over 4 days. In contrast, the smaller vancomycin molecules behaved very differently, with an initial burst release and a release time constant of up to 120 days by the denser hydrogels.

4.4.2 Systemic drug delivery-ELP micro- and nanoparticles have also been developed for circumstances in which local drug delivery by site injection or implantation is not feasible. Such particles comprise simple ELP polymers or di-block and tri-block copolymers, and can either enclose or be conjugated with drug molecules. ELP polymers of the form (VPAVG) 220 have been shown to self-assemble in physiological conditions into roughly spherical particles of $\sim 250 \mathrm{~nm}$ diameter ${ }^{[176]}$. These particles can encapsulate medically relevant quantities of bone morphogenic growth factors that have been pre-mixed with the ELP solution. In vitro testing showed an initial $15 \%$ burst release of the drug load, followed by a steady, sustained release over several days. The released growth factors retained osteoinductive activity as evidenced by osteoblast-like morphological changes in myoblast test cells, accompanied by a substantial increase in alkaline phosphatase production and calcium mineralization. Drug-laden ELP nanostructures can also be manufactured using an electrospray technique. ELPs mixed with a hydrophobic chemotherapeutic agent doxorubicin in water are electrosprayed to produce mainly spherical nanoparticles that encapsulate the drug ${ }^{[177]}$.

However, a limitation of these simple ELP nanoparticles is the burst release of drugs upon initial solubilization of the dried particles [177]. To overcome this problem, more stable structures have been sought. Di-block ELP copolymers of the form $(\mathrm{GVGVP})_{60}(\mathrm{GXGVP})_{64}$ (where $\mathrm{X}$ is Val:Gly:Ala in 1:7:8 ratio) ${ }^{[178]}$, and tri-block ELP copolymers with hydrophobic end-blocks and a hydrophilic core, can all form stable micelles above a transition temperature, as the hydrophobic regions collapse to the center of the structure and the hydrophilic components remain solvent-exposed. The micellar dimensions are tunable from $90-120 \mathrm{~nm}$ in a temperature-dependent manner ${ }^{[160,179]}$. ELP micelles are more stable than simple coacervates, and can be used to carry hydrophobic drugs through the circulatory system. Incorporation of tyrosine residues in the guest location of ELPs has been shown to increase the hydrophobicity of the micelle interior, enhancing their hydrophobic drugcarrying capability. The presence of cysteine residues at the core-shell interface increases micelle stability via disulfide bridge formation (Figure 5) ${ }^{[179]}$. Upon uptake into the intracellular environment, significantly increased levels of glutathione break the disulfide bonds ${ }^{[180]}$, destabilizing the micelles for targeted drug delivery ${ }^{[181]}$.

4.4.3 Tumor drug delivery-ELP drug delivery systems are particularly useful in cancer therapy (Figure 7). Tumors are characterized by leaky blood vessels and a scarcity of lymphatic vessels. Large molecule drug carriers such as ELPs infiltrate the tumor interstitium more easily than healthy tissue, and linger due to poor lymphatic drainage. ELPs have been found to preferentially accumulate in tumor tissue ${ }^{[182]}$ due to this enhanced permeability and retention effect ${ }^{[183]}$. However, tumor vasculature is unevenly distributed. This impedes ELP-drug diffusion into poorly-vascularized regions. Furthermore, the lack of lymphatic vessels prevents lymphatic convection-based drug transport within the tumor ${ }^{[184]}$. 
The local heating of solid tumors to $42{ }^{\circ} \mathrm{C}$ via focused microwaves, ultrasound or infrared illumination ${ }^{[185,186]}$ has been shown to increase tumor vascular permeability and improve the local accumulation of large molecules [187], such as ELPs designed to have a transition temperature between the physiological and hyperthermic tumor temperatures ${ }^{[188]}$.

Cellular penetration of the ELP drug carriers can be improved by engineering the ELPs to preferentially present peptide signal motifs such as RGD, NGR and penetratin in the micellar corona following self-assembly at the induced hyperthermic temperature [189]. These signal motifs are known cell receptor ligands, and consequently lead to increased cellular uptake of the decorated ELPs at $42{ }^{\circ} \mathrm{C}$, compared to undecorated ELPs or to decorated ELPs at $37^{\circ} \mathrm{C}$. ELP constructs designed for increased cellular uptake and functionalized with a c-Myc oncogenic protein inhibitory sequence ${ }^{[190]}$ have been reported to dramatically reduce the proliferation of human breast cancer cells over ten days after a single $1 \mathrm{hr}$ treatment ${ }^{[191]}$. This strategy of incorporating signal sequences to ELPs has since been expanded to other cell penetrating peptides and therapeutic peptides for cancer therapy (Figure 7) ${ }^{[186]}$.

4.4.4 Cartilage tissue engineering-Tissue repair and regeneration relies on physical and biochemical cues between cells and the ECM. Cells respond to matrix signals for growth, proliferation and differentiation, and, in turn, secrete substances which remodel the ECM [192]. An ideal artificial ECM mimics and supports this dual feedback loop [193]. The customizable design and properties of ELPs described previously make them highly suitable for engineering ECM-mimetic scaffolds. ELP scaffolds formed by thermal-responsive coacervation ${ }^{[166]}$, physical cross-linking ${ }^{[143]}$, or chemical cross-linking of ELP solutions ${ }^{[151]}$ have been developed for tissue repair.

Coacervated ELP materials with entrapped chondrocytes have been used to repair the nonregenerating articular cartilage. Despite the propensity of chondrocytes to de-differentiate when cultured outside of the native cartilage ECM, the ELP-encapsulated chondrocytes retain their characteristic rounded morphology and phenotype over 10 days, as shown by the accumulation of sulfated glycosaminoglycans and type II collagen ${ }^{[170]}$. Furthermore, the cells released from the coacervate matrix and cultured on a porous membrane are shown to be histologically and biochemically similar to native cartilage ${ }^{[194]}$. Following intra-articular injection [169], the ELP construct can induce chondrogenic differentiation of human adiposederived adult stem cells even in the absence of chondrocyte growth factors ${ }^{[195]}$.

Since cartilage is a load-bearing tissue, the ability to restore its mechanical function is highly paramount. Although coacervated ELP gels provide a suitable environment for chondrocyte growth and cartilage formation, they possess shear moduli that are four orders of magnitude below that of native articular cartilage [170,196], which limit their value in the regeneration of load-bearing tissues. To increase their stability and mechanical strength, ELP gels have been modified with additional glutamine and lysine residues to allow cross-linking by tissue transglutaminase ${ }^{[148]}$, an enzyme that has roles in cell growth and ECM organization [197]. The resulting cross-linked material exhibited a shear modulus two orders of magnitude greater than the ELP coacervate without loss of bioactivity ${ }^{[148,170]}$. 
To overcome the slow kinetics of transglutaminase cross-linking, ELP materials containing periodic lysines within the ELP component can be rapidly ( $<5 \mathrm{~min}$ ) polymerized by THPP in physiological conditions with water as the only by-product [151, 198, 199]. Crosslinked ELPs that are injected into a goat osteochondral defect, support cell infiltration and ECM production ${ }^{[199]}$.

The large number of variables involved in optimizing ELP constructs has led to the development of a neural network analysis system, in order to recognize patterns in the competing mechanical and biological outcomes of ELP materials designed specifically for cartilage repair. This approach may provide a useful set of tools for the design of ELP biomaterials for cartilage tissue engineering [200].

4.4.5 Vascular tissue engineering-Small-diameter vascular grafts often fail due to stenosis and thrombosis triggered by the proliferation of myofibroblasts. Graft failure has also been attributed to a mechanical mismatch with the native vessel and inadequate endothelial cell growth ${ }^{[150,201]}$. To address these issues, ELP materials can be tuned to match native tissue, and incorporated with biomimetically-spaced cell-signaling peptides for vascular applications. To illustrate, an ELP nonapeptide augmented at a 1:20 ratio with a GRGDSP fibronectin-derived cell binding sequence exhibited greatly increased aortic endothelial cell attachment and proliferation ${ }^{[202]}$ compared to the ELP alone ${ }^{[203]}$. An ELP implant material with a single GRGDSP sequence per polypeptide also promoted angiogenesis and the formation of an ECM with normal distribution of collagen and elastin ${ }^{[204]}$. Similarly, a glutaraldehyde-cross-linked ELP construct containing a fibronectinderived cell-adhesive sequence displayed a high affinity for endothelial cells [205]. Mechanically, ELP constructs integrated with signal sequences have tensile characteristics similar to native elastin [150, 206, 207].

4.4.6 Ocular tissue engineering-ELP scaffolds have also been designed to resemble the ECM of the ocular surface. The ELP component is based on the VPGIG repeat incorporated with VPGKG cross-link sequences, the fibronectin CS5 cell-binding sequence, and the VGVAPG protease target sequence. This functionalized material promotes the adhesion and growth of human conjunctival epithelial cells, while maintaining their differentiated phenotype as evidenced by the expression of characteristic protein markers ${ }^{[208]}$.

4.4.7 Bone tissue engineering-ELP polymers that rapidly solidify at body temperature have been investigated as potential candidates for bone repair and replacement. Bone scaffolds require load-bearing capabilities and must interface with inorganic crystalline materials, primarily hydroxyapatite. In addition, they must support bone tissue mineralization. ELP materials can be engineered to incorporate signaling motifs that activate bone cell growth and guide hydroxyapatite deposition. For example, ELPs designed to include the 15-residue calcium phosphate binding domain $\left(\mathrm{SN}_{\mathrm{A}} 15\right)$ from the salivary protein statherin facilitated the formation of well-structured HA deposits. Both the scaffold nanostructure and the density of $\mathrm{SN}_{\mathrm{A}} 15$ domains are thought to be essential for calcium phosphate accumulation ${ }^{[209]}$. 
The morphological tunability of ELP scaffolds is beneficial in bone applications. Spincoated micro-and nano-patterned ELP membranes with an RGDS-based cell attachment sequence are shown to undergo a three-fold increase in surface stiffness from $5 \mathrm{MPa}$ to more than $15 \mathrm{MPa}$ as the temperature was increased to above the ELP transition temperature. The presence of RGDS sequences and topographical patterns significantly increased rat mesenchymal stem cell adhesion and spreading [210]. The further addition of $\mathrm{SN}_{\mathrm{A}} 15$ domains to ELPs enhanced osteoblastic differentiation of these cells as measured by increased osterix expression, to levels surpassing that of cells grown in an osteogenic differentiation medium ${ }^{[211]}$. Accordingly, this ELP material improves bone regeneration when implanted in rat bone defects ${ }^{[211]}$.

4.4.8 Neural tissue engineering - Neural tissues possess limited regenerative capacity, and are therefore rarely able to bridge large defects caused by injury or disease of the nervous system. ELP constructs have been developed for their ability to guide neurite extension. As an example, ELP hydrogels containing the RGDS cell-adhesion signal sequence and cross-linked with the amine-reactive tetrakis(hydroxymethyl)phosphonium chloride were fabricated for axon and dendrite outgrowth ${ }^{[212]}$. These materials possess a compressive elasticity of 0.5-2.1 kPa, consistent with the low stiffness of soft tissues. A twolayered, concentric tubular conduit composed of external and internal ELP gel layers has demonstrated in vitro biocompatibility, successfully inducing neurite outgrowth of transplanted dorsal root ganglion cells to greater than $1 \mathrm{~mm}$ in these 3D constructs. This considerable achievement has encouraged further development of ELP-based conduits capable of supporting aligned nerve fiber growth vital for clinical use ${ }^{[212]}$.

\section{Composite ELP-based materials}

Pure ELP constructs can be incorporated with other peptide, protein, polysaccharide, or polymer moieties to enable the fabrication of more complex architectures, or to augment the mechanical and functional properties of existing materials. A range of structures such as nanoparticles, hydrogels, sheets or films, tubes, and nanofibers are engineered from composite ELP-based materials (Table 6).

\subsection{Composite ELP-based nanoparticles}

5.1.1 Fabrication-ELP-based nanoparticles are typically formed from the spontaneous, entropy-driven self-assembly of monomer blocks composed of segments with differential hydrophobicity. In aqueous solution, the nanoparticles are marked by a hydrophobic core and a hydrophilic corona ${ }^{[141]}$. The monomer may be a co-polypeptide block, defined by the peptide nature of both hydrophobic and hydrophilic groups. For instance, nanoparticles have been constructed from blocks consisting of a hydrophobic ELP and a hydrophilic silkderived GAGAGS peptide ${ }^{[213]}$. Alternatively, the monomer may be a hybrid polypeptidepolymer block, composed of a hydrophobic ELP and a hydrophilic compound such as polyethylene glycol (PEG) ${ }^{[214]}$. The ELP moiety may also be directly conjugated to a functional cargo within the monomer block, as illustrated by the fusion of a hydrophilic ELP to a hydrophobic chemotherapeutic doxorubicin drug ${ }^{[215]}$, or to the keratinocyte growth factor ${ }^{[216]}$. The range of molecules that can be ligated to an ELP sequence without loss of 
self-assembly properties is dictated by hydrophobicity rather than size, as supported by the successful ELP-fusion of molecules above $10 \mathrm{kDa}{ }^{[217]}$. The hydrophobicity of targets can be quantified by their $\log \mathrm{D}$ octanol-water distribution coefficient, which ranges from -1.0 for hydrophilic groups up to 4.0 for hydrophobic groups. Nanoparticle assembly remains unaffected when targets with hydrophobic values greater than 1.5 are attached to hydrophilic ELPs ${ }^{[218]}$.

Apart from a self-assembly process, ELP-containing nanoparticles can be fabricated by grafting or adsorbing ELPs onto existing micellar constructs. ELPs have been terminally modified with a hydrocarbon tail, such as a stearyl group, to allow incorporation into a liposome bilayer via hydrophobic interactions (Figure 8) ${ }^{[219]}$. ELP solutions have also been used to coat calcium carbonate particles enveloping drug cargoes, followed by the removal of the $\mathrm{CaCO}_{3}$ templates via EDTA chelation ${ }^{[220]}$.

5.1.2 Properties-Composite ELP-based nanoparticles can be engineered to sizes ranging from $40 \mathrm{~nm}$ to above $200 \mathrm{~nm}$ [20, 213, 214, 221] [219]. The particles typically display a spherical morphology under the transmission electron microscope, consistent with the globular burying of hydrophobic regions from an aqueous environment ${ }^{[214]}$. However, as the selfassembly process is not solely determined by hydrophobic associations, but also by stoichiometry-driven polar interactions between residues, the nanoparticles can also form various structures including cylindrical micelles and star-like congregates ${ }^{[222]}$. It is thought that monomer units with hydrophilic weight fractions between $25-45 \%$ form vesicles, while those between $45-55 \%$ form cylindrical structures ${ }^{[223]}$.

Composite ELP-based nanoparticles retain the thermal responsiveness of ELPs despite the inclusion of additional functional groups or compounds within the ELP block ${ }^{[216,224]}$. In aqueous solutions below the ELP transition temperature, the hydrogen bonds between the ELPs and the solvent molecules hold the nanoparticles in solution ${ }^{[219,225]}$. Above the transition temperature, ELPs undergo conformational change from random coils to betaturns and the nanoparticles coacervate owing to the strong hydrophobic interactions between ELP blocks.

5.1.3 Application in drug delivery-As with pure ELP nanoparticles, ELP-containing composite nanoparticles are manufactured predominantly as high-load drug delivery systems ${ }^{[224]}$. The attachment of drug molecules to ELP sequences may sometimes decrease therapeutic activity due to steric hindrances, as illustrated by an 80 -fold reduction in the cytokine activity of the ELP-interleukin 10 fusion protein compared to interleukin 10 alone ${ }^{[221]}$. Nevertheless, there is strong evidence for sufficient activity of nanoparticledelivered drugs. For example, the administration of nanoparticles assembled from ELPs fused with keratinocyte growth factor, which is involved in epidermal porphogenesis and normally upregulated after injury, has been shown to induce fibroblast proliferation and keratinocyte migration, enhance epidermal regeneration and improve full-thickness wound healing in diabetic mice ${ }^{[216]}$. These therapeutic benefits were not observed when ELPs were simply blended with the growth factor ${ }^{[216]}$, indicating the importance of the composite nature of the nanoparticles to their efficacy. This rationale similarly underlies the motivation to integrate ELPs into existing drug delivery vehicles, such as to liposomes ${ }^{[226]}$ or to gold 
nanoparticles ${ }^{[227]}$. The presence of ELPs confers characteristic thermal, salt and $\mathrm{pH}$ responsiveness to these systems for controllable drug release ${ }^{[228]}$.

Composite ELP-based nanoparticles are highly suitable as drug delivery vehicles due to a number of factors. First, they are biocompatible and elicit minimal human immunogenic responses ${ }^{[224]}$. They are also biodegradable over the time course of drug delivery, losing approximately $2.5 \%$ mass per day ${ }^{[229]}$. Studies have shown that ELP-based nanoparticles have reduced toxicity compared to a polyethylenimine control ${ }^{[230]}$.

Second, nanoparticles can protect labile drugs from the environment and preserve drug bioactivity ${ }^{[224]}$. This was illustrated by a reduction in the enzymatic degradation of coacervated nanoparticles due to the decreased accessibility of the hydrophobic core ${ }^{[231]}$. However, any engineered stability of the nanoparticle membrane must be balanced between the requirements for drug protection and subsequent drug release ${ }^{[219]}$.

Third, ELP-based nanoparticles have a highly tunable response to stimulus. The sequence and length of the ELP component, the relative ELP concentration, and the linker length between the ELP and its attached group can all be manipulated to tailor the coacervation temperature of the nanoparticles ${ }^{[222]}$. This transition temperature can be judiciously selected to target delivery of nanoparticles only to areas where local hyperthermia has been induced by microwaves, radiofrequency, or ultrasound ${ }^{[188]}$. The nanoparticle preparation can therefore be injected as soluble monomers prior to self-assembly in defined areas. As evidence, ELP-based nanoparticles only aggregated in tumors under hyperthermic conditions, but not in physiological temperatures ${ }^{[221]}$. Such a temperature-sensitive, selfassembling drug delivery system has been successfully demonstrated with various inhibitor and cell lytic peptides ${ }^{[221]}$.

The thermal responsiveness of ELP-based nanoparticles can also be exploited for the highlevel, controlled release of drug cargoes. Small molecular weight therapeutic agents often diffuse rapidly from the target site, making it difficult to maintain a critical concentration for bioactivity ${ }^{[232]}$. The conjugation of such compounds to ELP allows an initial bolus of drug to be released during nanoparticle aggregation, followed by a sustained release during elastase degradation of the nanoassemblies ${ }^{[233]}$. On the other hand, in micelles where functionalized ELPs are inserted within the lipid bilayer, temperature-induced conformational denaturation of ELPs destabilize the membrane and trigger the release of encapsulated contents ${ }^{[219]}$. It has been shown that majority of a drug is liberated only above the transition temperature of the ELP-containing nanoparticles. The kinetics of drug release is dictated by the ELP component, with increased ELP hydrophobicity associated with a slower release due to an increased affinity for the hydrophobic cargo ${ }^{[234]}$. Drug release can be further tuned by ligating the cognate drug receptor to the ELP segment. The higher affinity between the drug and its receptor compared to that between the drug and ELP enables a biphasic release profile, characterized by a fast release from the ELP core, and a slower release from the receptor ${ }^{[234]}$. Importantly, the ability to control drug release improves its efficacy and tolerability at higher doses ${ }^{[234]}$. 
Fourth, the capacity of ELPs to accommodate sequence modifications without loss of selfassembly properties conveniently enables the conjugation of additional functional moieties. ELP unimers have been functionalized with cleavable, reactive sites for tethering small molecules ${ }^{[215]}$. Purification of the resulting chimeric ELP-based blocks is also simplified by employing sequential temperature changes to selectively precipitate and solubilize the product while eliminating impurities.

Finally, composite ELP-based nanoparticles can be tailored to for specific cell penetrability ${ }^{[214]}$. While they are already taken up by cells via endocytosis through hydrophobic regions, additional cell-specific targeting peptides can be incorporated for improved cellular uptake or delivery to specific tissues. For instance, nanoparticles displaying the CD13 ligand can preferentially target tumors which overexpress the CD13 receptor ${ }^{[134]}$. Enhanced target selectivity of nanoparticles reduces the side effects borne from systemic exposure to drugs, and allows the treatment of areas such as articular tissue that are not easily accessible via systemic drug administration ${ }^{[221] .}$

\subsection{Composite ELP-based hydrogels/sponges}

5.2.1 Fabrication-Pure ELPs can form cross-linked hydrogels, either by chemical functionalization of the ELP block with reactive groups ${ }^{[225,232]}$, or by the addition of an external cross-linking agent ${ }^{[235]}$. Many studies have also been undertaken on the construction of composite ELP-based hydrogels. A simple method of fabrication involves the addition of ELPs to a material that naturally undergoes gelation ${ }^{[236]}$. ELPs mixed with collagen solutions form hydrogels when incubated at $37{ }^{\circ} \mathrm{C}$ with no additional need for cross-linkers, due to both direct interactions and water-mediated hydrogen bonding between the two components ${ }^{[237]}$. ELPs combined with fibrinogen and thrombin form sponges after covalent bonding between ELPs and fibrin monomers generated from thrombin cleavage of fibrinogen ${ }^{[238]}$.

In other cases, ELPs are grafted with functionally and/or compositionally important peptides or polymers that do not self-assemble, necessitating the use of cross-linking agents for hydrogel formation. For structural advantages, PEG has been fused to ELPs and cross-linked with tris(hydroxymethyl)phosphine to form hydrogels ${ }^{[239]}$. The addition of PEG decreases the light scattering and improves the optical transparency of pure ELP hydrogels, while the presence of ELPs bypasses the complicated chemistry required to tailor the mechanical properties of pure PEG materials ${ }^{[239]}$. Often, peptides and proteins ligated to ELPs serve a functional purpose. Composite hydrogels of ELP and a thiol-modified hyaluronan crosslinked with polyethylene diacrylate mimic the intervertebral disc environment in which both elastin and hyaluronan reside ${ }^{[233]}$. ELP blocks blended with fibronectin prior to genipin cross-linking provide enhanced cell activity ${ }^{[240]}$. On other occasions, ELP-fused compounds contribute both morphological and functional roles. Hydrogels have been produced from a chimeric ELP containing a salivary statherin derivative involved in mineral regulation on the dental enamel surface. Such substrates exude biochemical and topographical signals to modulate biomineralization ${ }^{[241]}$.

ELPs can also be incorporated by surface adsorption onto pre-formed hydrogels such as collagen foams ${ }^{[242]}$. 
5.2.2 Properties-Composite ELP-based hydrogels can be molded into a defined architecture, but as an independent entity, their growth is governed by the shape of isolated ELP-based chains ${ }^{[225]}$. When formed below the transition temperature, hydrogels have a linear shape similar to the extended, hydrated ELP molecular structure and result from the zipper-like cross-linking orientation in the extended chains. Above the transition temperature, hydrogels follow the globular molecular shape of the ELP, in which apolar domains bury within a core while polar domains remain solvent-exposed ${ }^{[225]}$.

These composite hydrogels have highly tunable mechanical and chemical properties, with additional control often being afforded by the integration of ELP and non-ELP components ${ }^{[243]}$. For instance, the addition of ELPs to hyaluronan hydrogels improves mechanical strength and stiffness ${ }^{[244]}$. Similarly, hydrophobic interactions between ELP and carbon nanosphere chains enhance the strength of such composite hydrogels ${ }^{[245]}$. ELPcollagen hydrogels also have a higher tensile strength arising from stronger intermolecular bonding [237, 243, 245], and a lower elastic modulus ${ }^{[245]}$. Hybrid ELP-PEG hydrogels likewise display lower shear storage and elastic moduli ${ }^{[239]}$. Hydrogel porosity, additionally, can be controlled not only by the choice of cross-linker, but also by the fabrication method of such hybrid materials ${ }^{[242]}$. Adsorbing ELPs on a collagen foam reduced scaffold porosity, while blending the ELPs with collagen prior to hydrogel formation resulted in an open porous composition. The fiber thickness of composite hydrogels can also be tailored, as evidenced by the decrease in fiber diameter by three orders of magnitude upon the addition of ELPs to collagen scaffolds ${ }^{[242]}$. Furthermore, the zeta potential of hydrogels can also be altered, based on the temperature-dependent exposure of engineered lysines on the external hydrogel surface ${ }^{[225]}$.

The ability to modulate these structural properties is vital for defining material functionality. To illustrate, scaffolds with a higher elastic modulus can influence cell fate, for example by triggering osteoblast differentiation ${ }^{[246]}$, or by inducing endothelial cell switching from a monolayer to tubular morphology [240]. In other biomedical applications, excessive scaffold stiffness may lead to pain, restricted mobility, or hypertrophic scarring ${ }^{[233]}$. Hydrogels for dermal repair are not therapeutic when their pore sizes fall outside the 20-120 $\mu \mathrm{m}$ window optimal for fibroblast migration [247]. Consequently, variable channel structures within one material can restrict the growth of specific cell types to distinct areas, which may be useful for the segregated co-culture of cells to mimic a tissue environment ${ }^{[248]}$. Even the architecture of hydrogel fibers affects cell phenotype, as shown by the extension of smooth muscle cells along the fiber length to potentially increase cell-material contact [249].

Composite hydrogels also possess increased stability. ELP-silk hydrogels remained stable in solution for $>2$ months, in contrast to pure ELP constructs which disintegrated after one day ${ }^{[250]}$. This is due to the stronger hydrogen bonding between beta-sheets in silk compared to the hydrophobic contacts within an ELP-only material. Similarly, pure collagen materials are susceptible to degradation by collagenases, which in turn can elicit inflammation or fibrous capsule formation ${ }^{[251]}$. The incorporation of a more hydrophobic ELP component reduces hydrophilicity and accessibility to degradation enzymes ${ }^{[245]}$. 
Importantly, composite ELP-based hydrogels exhibit biocompatibility ${ }^{\text {[244]. ELP-collagen }}$ hydrogels have been shown to promote increased osteoblast proliferation while maintaining phenotypic alkaline phosphatase and osteocalcin marker expression and cell function [236]. ELP-hyaluronan hydrogels similarly maintain prolonged intervertebral disc cell viability and phenotype ${ }^{[244]}$. Since canonic ELP sequences generally do not support cell growth, hydrogel biocompatibility can be further enhanced by functionalising the ELP segment with cell-binding ligands such as the RGD motif ${ }^{[239]}$, or cell-adhesive proteins such as fibronectin. Indeed, fibroblasts have been found to penetrate the thickness of an RGDfunctionalised ELP-collagen hydrogel and develop a stratified epithelial layer ${ }^{\text {[242] }}$. Likewise, cells grown on ELP-fibronectin hydrogels exhibit extensive actin stress fibers and vinculin clusters ${ }^{[240]}$.

5.2.3 Applications-Composite ELP-based hydrogels are utilized in a range of applications. They can be used for drug delivery, particularly in areas that are not amenable to systemic injection or topical application ${ }^{[237]}$.

The ability to construct composite hydrogels with properties closely resembling the charged, hydrated native extracellular matrix environment has enabled their use as an ECM-mimetic scaffold. An injectable preparation can be introduced in liquid phase, which can phase transition into a gel at physiological temperature within a short 10-15 min time frame ${ }^{[244]}$. ELP-hyaluronan hydrogels have been administered in this manner into the intervertebral disc during early stages of disc degeneration to structurally augment the nucleus pulposus and restore spinal motion ${ }^{[244,252]}$. Likewise, injectable ELP-calcium phosphate composites have been developed, in which the components mix into a hydroxyapatite cement reminiscent of the mineral component of bones and teeth ${ }^{[253]}$. Such composite hydrogels have been used as dental implant placements and alveolar bone fillings due to their mechanical stability and porosity suited for new tissue formation ${ }^{[254]}$. ELP-collagen-fibrin scaffolds, characterised by their fine fibrous structure resembling native fascia temporalis, have been applied for the closure of tympanic membrane perforations ${ }^{[238]}$.

These ECM-mimetic hybrid hydrogels act as a favorable substrate for cell growth, as demonstrated by the attachment and proliferation of endothelial cells on hydrogels manufactured from ELP and a VEGF angiogenic growth factor derived peptide [232] Hydrogels developed as nerve conduits for peripheral nerve regeneration support Schwann cell adhesion and proliferation ${ }^{[235]}$. Accordingly, these hydrogels can also entrap cells with high viability ${ }^{[232]}$, due to their high water content, cytocompatibility, and extracellular matrix-mimetic structure and mechanics [237]. This was demonstrated when cells mixed with solubilised ELP-collagen were encapsulated within the matrix of the resulting hydrogel [243]. ELP-based hybrid materials not only support cell viability, they can also actively modulate cellular responses, including cell cycle progression, cytoskeleton development, migration, differentiation, and extracellular matrix establishment ${ }^{[240]}$. ELP-collagen scaffolds have been reported to induce rapid microtubular network formation by contractile cells, sustain endogenous elastin and elastic fiber production ${ }^{[243,255]}$, and increase calcium ion recruitment for osteoblast differentiation and mineralization ${ }^{[241]}$. Furthermore, these biochemical cues may be targeted to a particular cell type, allowing selective culture of a subpopulation of cells within a tissue milieu ${ }^{[233]}$. In support, an ELP-collagen material 
preferentially supported the proliferation of endothelial cells and smooth muscle cells over fibroblasts ${ }^{[233]}$.

Composite ELP-based hydrogels possess additional features that make them suitable for tissue replacement. For instance, a primary limitation of many scaffolds is insufficient vascularization. As solubilized elastin promotes angiogenesis, ELP addition to collagen scaffolds stimulates endothelial cell migration and tubule formation for increased vascularisation ${ }^{[255]}$. Likewise, an ELP-collagen-fibrin material has been found to induce capillary proliferation in a subcutaneous implant ${ }^{[238]}$. In addition, while inflammation occurs during normal wound healing to trigger re-epithelialization and angiogenesis [256], persistent inflammation is undesirable. A number of composite ELP-based scaffolds elicited inflammatory responses only in the initial stages of implantation ${ }^{[238,255,257]}$. Unwanted calcification of the implanted constructs can also be minimized by incorporating negativelycharged groups to prevent calcium ion precipitation ${ }^{[255]}$.

\subsection{Composite ELP-based nanofibers}

5.3.1 Fabrication-Numerous studies on the fabrication of ELP-based nanofibers conjugate silk fibroin-derived peptides such as GAGAGS to ELPs to form silk-elastin-like protein polymers (SELP) ${ }^{[258]}$. While silk-like motifs can produce stable, beta-sheet rich fibrillar structures, the kinetics of formation is slow, in contrast to the instantaneous selfassembly of ELPs above the transition temperature ${ }^{[250]}$. The distribution of silk blocks within ELP segments, followed by purification via inverse temperature cycling, prevents premature irreversible beta-sheet formation between silk blocks ${ }^{[259]}$. Above the ELP transition temperature, the soluble monomers nucleate into filaments, which in turn associate laterally into nanofibers ${ }^{[250]}$. The nanofibers are stabilized by electrostatic attractions between the oppositely-charged head and tail tags of SELP monomers, hydrogen bonds between beta-sheets in a beta-roll structure, and hydrophobic associations between beta-rolls within the stacked core ${ }^{[259,260]}$. These processes enable rapid temperature-dependent SELP fiber assembly ${ }^{[250]}$.

Wet spinning is another method of producing ELP-silk nanofibers ${ }^{[261]}$. This technique involves extruding an ELP-silk solution in a thread-like form into methanol/water to coagulate into fibers. The fibers are dried and stabilized by cross-linking. Fiber diameter is controlled by the spinneret size and the drawing of fibers during collection. Fiber patterning can also be directed by mechanical stimuli to induce nucleation along an orientation ${ }^{262]}$.

ELPs have additionally been combined with other polymers such as polycarbonateurethane, or proteins such as collagen, to form ECM-mimetic fibrous constructs via electrospinning ${ }^{[263]}$.

5.3.2 Properties-The assembly of composite ELP-based nanofibers can be controlled to give rise to variable properties. The fibrillar structure is governed by a threshold monomer concentration, and facilitated by monomer-surface interactions ${ }^{[260]}$. Surfaces with a negative charge density encourage attraction by the positively-charged SELPs at neutral $\mathrm{pH}$. Conversely, uncharged hydrophobic surfaces do not allow nanofiber formation. These surface contacts are adversely affected by increased solution ionic strength, which also 
reduces repulsive interactions between SELPs and potentially leads to aggregation-induced retardation of fiber assembly ${ }^{[260]}$. In addition, the type of surface also affects nanofiber morphology, as demonstrated by variable lengths of fibers grown on different negativelycharged surfaces ${ }^{[260]}$. Furthermore, fiber morphology and architecture can be tuned by engineering the SELP monomer itself. The number of silk blocks per monomer has been associated with the smoothness of the fiber surface, as well as fiber yield during wet spinning ${ }^{[261]}$. The size of silk blocks and the charge of ELP blocks both affect beta-roll folding and stacking into the nanofibers core ${ }^{[259]}$.

Composite ELP-based nanofibers are stable, maintaining fiber morphology for up to a month in solution, and remaining fiber integrity for up to a year ${ }^{[261]}$. These constructs display increased mechanical properties when annealed above the transition temperature of the monomer blocks ${ }^{[250]}$. As with most ELP-based materials, the composite ELP-based nanofibers also maintain thermal responsiveness $[213,264]$.

The biocompatibility of these nanofibers also lend themselves as potential niches for cell production ${ }^{[250]}$.

\subsection{Composite ELP-based sheets/films}

5.4.1 Fabrication-The fabrication of multi-lamellar sheets has largely been motivated by the need for native tissue mimetics ${ }^{[265]}$. One method of production is the layer-by-layer technology, which utilizes electrostatic attractions between oppositely-charged surfaces ${ }^{[266]}$, or hydrogen bonding and hydrophobic interactions [267], to drive the consecutive assembly of layers (Figure 9). Surface charge is induced by the adsorption of charged polyelectrolytes, and can also be utilized to bind biologically active ligands. Hybrid sheets have been manufactured in this manner from alternating depositions of ELP and chitosan solutions on glass slides [266], as well as from ELP and polysaccharide on quartz crystals [267].

In addition, composite ELP-based nanofilms can be formed from solvent evaporation of hybrid ELP solutions into sheets ${ }^{[268]}$, or electrospinning into mats which are subsequently stabilized by exposure to methanol-saturated air ${ }^{[258]}$. Composite films can also be made from pure ELP polymer sheets reinforced with collagen microfibers and functionalized with fibronectin for cell binding ${ }^{[240]}$. Collagen fibers are wound onto frames, embedded with an ELP solution, pressed and heated to aid interlamellar cohesion, then cross-linked for stability [269].

5.4.2. Properties-Composite ELP-based films can be fabricated to defined properties. Synthesized films possess fiber diameters of $50 \mathrm{~nm}$ to $>60 \mathrm{um}^{[261,270]}$, depending on a range of parameters including the ELP-hybrid sequence, its concentration in solution, and the solution viscosity ${ }^{[258]}$. The density of the sheet fibers, as well as their relative lateral orientation, can all be tailored to resemble the geometry of native tissues and facilitate cell penetrability ${ }^{[271]}$. The overall thickness of the film and the multi-lamellar organization can also be altered to influence the retention of reagents enveloped within the layered structure ${ }^{[265]}$. The biodegradability of the constructs can likewise be modified by changing the molecular composition of the ELP-based monomers ${ }^{[258]}$. Furthermore, even in a multi- 
layered assembly such as nanofilms, ELPs respond to thermal stimuli, although the selfassociation of polymer chains is less efficient compared to that in solution ${ }^{[266]}$.

Hybrid ELP-based films/sheets support high cell viability, promoting both cell adhesion and proliferation ${ }^{[258]}$, while maintaining cell activity and phenotype ${ }^{[240]}$. When implanted in subcutaneous and intraperitoneal spaces, an ELP-collagen film elicited minimal inflammatory response over 3 weeks ${ }^{[265]}$. This is consistent with findings that negligible quantities of these materials leach into the culture medium, with no toxic effects [258, 267].

5.4.3. Applications-Composite ELP-based films have been used as a system to encapsulate and deliver pharmaceuticals, such as the antibiotic rapamycin ${ }^{[234]}$ and ophthalmic drugs ${ }^{[272]}$. They have also been developed as a wound dressing material, particularly for moderately exuding wounds due to their ability to transmit water vapour from the wound bed to the external environment ${ }^{[258]}$. In addition, these multi-layered constructs are valuable in soft tissue engineering [240]. Their structural resemblance to the lamellar characteristics of tissues, such as the intervertebral disc, arterial media and abdominal wall fascia, render them suitable as replacement scaffolds to incorporate cells before or after implantation ${ }^{[273]}$. As evidence, an ELP-collagen sheet material has been demonstrated to mechanically support a full-thickness abdominal wall defect ${ }^{[265]}$.

\section{Summary}

The intrinsic structural, biological, and assembly properties of elastin and its derivatives can be harnessed to fabricate a wide range of materials that both instruct and respond to cells. The incorporation of other synthetic or natural polymers or sequence motifs further enhances the biomaterial potential of these elastin-based constructs. The array of engineering techniques for elastin-based materials allows precise control over the resulting architectural features to meet the specific mechanical and functional requirements of diverse applications. Our increasingly refined understanding of elastin fabrication will enable these techniques to be reproducibly implemented on a commercial scale. We envisage a translational expansion of elastin-based and elastin-derived tissue engineering products in the near future. For instance, the first commercial tropoelastin injectable product for tissue repair is expected to be on the market in Europe by 2016. We believe that this development heralds the beginning of widespread availability and use of elastin materials in biomedicine and tissue engineering.

\section{References}

1. Bellingham CM, Keeley FW. Current Opinion in Solid State and Materials Science. 2004; 8:135.

2. Powell JT, Vine N, Crossman M. Atherosclerosis. 1992; 97:201. [PubMed: 1466664]

3. Vrhovski B, Weiss AS. European Journal of Biochemistry. 1998; 258:1. [PubMed: 9851686]

4. Anwar, G. E. G. a. R. A. Journal of Biological Chemistry. 1974; 249:5200. [PubMed: 4854426]

5. Bax DV, Rodgers UR, Bilek MM, Weiss AS. The Journal of biological chemistry. 2009; 284:28616. [PubMed: 19617625]

6. Lee P, Bax DV, Bilek MM, Weiss AS. The Journal of biological chemistry. 2014; 289:1467.

[PubMed: 24293364] 
7. Cox BA, Starcher BC, Urry DW. Journal of Biological Chemistry. 1974; 249:997. [PubMed: 4359779]

8. Senior RM, Griffin GL, Mecham RP, Wrenn DS, Prasad KU, Urry DW. The Journal of Cell Biology. 1984; 99:870. [PubMed: 6547961]

9. Rodgers UR, Weiss AS. Biochimie. 2004; 86:173. [PubMed: 15134831]

10. Hiob MA, Wise SG, Kondyurin A, Waterhouse A, Bilek MM, Ng MK, Weiss AS. Biomaterials. 2013; 34:7584. [PubMed: 23863453]

11. Almine JF, Wise SG, Hiob M, Singh NK, Tiwari KK, Vali S, Abbasi T, Weiss AS. FASEB journal : official publication of the Federation of American Societies for Experimental Biology. 2013; 27:3455. [PubMed: 23671273] Rodgers UR, Weiss AS. Pathologie-biologie. 2005; 53:390. [PubMed: 16085115]

12. Yeo GC, Keeley FW, Weiss AS. Advances in Colloid and Interface Science. 2011; 167:94. [PubMed: 21081222]

13. Urry DW. Scientific American. 1995; 272:64.

14. Bellingham CM, Woodhouse KA, Robson P, Rothstein SJ, Keeley FW. Biochimica et biophysica acta. 2001; 1550:6. [PubMed: 11738083]

15. Bellingham CM, Lillie MA, Gosline JM, Wright GM, Starcher BC, Bailey AJ, Woodhouse KA, Keeley FW. Biopolymers. 2003; 70:445. [PubMed: 14648756]

16. Hinek A, Rabinovitch M. The Journal of biological chemistry. 1993; 268:1406.

17. Wu WJ, Weiss AS. European Journal of Biochemistry. 1999; 266:308. [PubMed: 10542079]

18. Zhang MC, He L, Giro M, Yong SL, Tiller GE, Davidson JM. Journal of Biological Chemistry. 1999; 274:981. [PubMed: 9873040]

19. Hsaio H, Stone PJ, Toselli P, Rosenbloom J, Franzblau C, Schreiber BM. Connective Tissue Research. 1999; 40:83. [PubMed: 10761633] Kozel BA, Wachi H, Davis EC, Mecham RP. The Journal of biological chemistry. 2003; 278:18491. [PubMed: 12626514]

20. MacEwan SR, Chilkoti A. Peptide Science. 2010; 94:60. [PubMed: 20091871]

21. Rosenbloom J. Methods in enzymology. 1987; 144:172. [PubMed: 3306283]

22. Moczar M, Moczar E, Robert L. Connect Tissue Res. 1979; 6:207. [PubMed: 38948]

23. Partridge SM, Davis HF, Adair GS. Biochemical Journal. 1955; 61:11. [PubMed: 13260170]

24. Indik Z, Abrams WR, Kucich U, Gibson CW, Mecham RP, Rosenbloom J. Archives of Biochemistry and Biophysics. 1990; 280:80. [PubMed: 2191629]

25. Martin SL, Vrhovski B, Weiss AS. Gene. 1995; 154:159. [PubMed: 7890158]

26. Heydarkhan-Hagvall S, Schenke-Layland K, Dhanasopon AP, Rofail F, Smith H, Wu BM, Shemin R, Beygui RE, MacLellan WR. Biomaterials. 2008; 29:2907. [PubMed: 18403012]

27. Machula H, Ensley B, Kellar R. Advances in wound care. 2014; 3:367. [PubMed: 24804156]

28. Baumgarten PK, Colloid Sci J. 1971; 36:71.

29. Nivison-Smith L, Weiss AS. Journal of biomedical materials research. Part A. 2012; 100:155. [PubMed: 21997972]

30. Wise SG, Byrom MJ, Waterhouse A, Bannon PG, Weiss AS, Ng MK. Acta biomaterialia. 2011; 7:295. [PubMed: 20656079]

31. Reneker DH, Chun I. Nanotechnology. 1996; 7:216.

32. Taylor G. Proceedings of the Royal Society A: Mathematical, Physical and Engineering Sciences. 1964; 280:383.

33. Huang Z-M, Zhang YZ, Kotaki M, Ramakrishna S. Composites Science and Technology. 2003; 63:2223.

34. Almine JF, Bax DV, Mithieux SM, Nivison-Smith L, Rnjak J, Waterhouse A, Wise SG, Weiss AS. Chemical Society reviews. 2010; 39:3371. [PubMed: 20449520]

35. Nivison-Smith L, Rnjak J, Weiss AS. Acta biomaterialia. 2010; 6:354. [PubMed: 19671457]

36. Wise SG, Mithieux SM, Weiss AS. Advances in Protein Chemistry and Structural Biology. 2009; 78:1. [PubMed: 20663482]

37. Li M, Mondrinos MJ, Gandhi MR, Ko FK, Weiss AS, Lelkes PI. Biomaterials. 2005; 26:5999. [PubMed: 15894371] 
38. Rnjak J, Li Z, Maitz PK, Wise SG, Weiss AS. Biomaterials. 2009; 30:6469. [PubMed: 19712968]

39. Zeugolis DI, Khew ST, Yew ES, Ekaputra AK, Tong YW, Yung LY, Hutmacher DW, Sheppard C, Raghunath M. Biomaterials. 2008; 29:2293. [PubMed: 18313748]

40. Zou Y, Zhang Y. Annals of biomedical engineering. 2009; 37:1572. [PubMed: 19484387]

41. Rnjak-Kovacina J, Wise SG, Li Z, Maitz PK, Young CJ, Wang Y, Weiss AS. Biomaterials. 2011; 32:6729. [PubMed: 21683438]

42. Annabi N, Mithieux SM, Camci-Unal G, Dokmeci MR, Weiss AS, Khademhosseini A. Biochemical engineering journal. 2013; 77:110. [PubMed: 23935392]

43. Hettiaratchy S, Dziewulski P. BMJ. 2004; 328:1366. [PubMed: 15178618] van der Veen VC, van der Wal MB, van Leeuwen MC, Ulrich MM, Middelkoop E. Burns : journal of the International Society for Burn Injuries. 2010; 36:305. [PubMed: 19897310]

44. Rubis BA, Danikas D, Neumeister M, Williams WG, Suchy H, Milner SM. Burns : journal of the International Society for Burn Injuries. 2002; 28:752. [PubMed: 12464473]

45. Guan J, Stankus JJ, Wagner WR. Cell Transplant. 2006; 15:17.

46. Dallon JC, Ehrlich HP. Wound repair and regeneration : official publication of the Wound Healing Society [and] the European Tissue Repair Society. 2008; 16:472.

47. Tu Y, Wise SG, Weiss AS. Micron. 2010; 41:268. [PubMed: 19969467]

48. Mithieux SM, Rasko JE, Weiss AS. Biomaterials. 2004; 25:4921. [PubMed: 15109852]

49. Mithieux SM, Weiss AS. Adv Prot Chem. 2005; 70:437.

50. Annabi N, Mithieux SM, Weiss AS, Dehghani F. Biomaterials. 2010; 31:1655. [PubMed: 19969349]

51. Quirk RA, France RM, Shakesheff KM, Howdle SM. Current Opinion in Solid State and Materials Science. 2004; 8:313.

52. Ma PX. Advanced drug delivery reviews. 2008; 60:184. [PubMed: 18045729]

53. Fung, YC. Biomechanics. Mechanical properties of living tissues. Springer; New York: 1993.

54. Annabi N, Mithieux SM, Boughton EA, Ruys AJ, Weiss AS, Dehghani F. Biomaterials. 2009; 30:4550. [PubMed: 19500832]

55. Dehghani F, Annabi N, Valtchev P, Mithieux SM, Weiss AS, Kazarian SG, Tay FH. Biomacromolecules. 2008; 9:1100. [PubMed: 18363358]

56. Annabi N, Mithieux SM, Weiss AS, Dehghani F. Biomaterials. 2009; 30:1. [PubMed: 18842297]

57. Annabi N, Tsang K, Mithieux SM, Nikkhah M, Ameri A, Khademhosseini A, Weiss AS. Advanced functional materials. 2013:23.

58. Annabi N, Mithieux SM, Zorlutuna P, Camci-Unal G, Weiss AS, Khademhosseini A. Biomaterials. 2013; 34:5496. [PubMed: 23639533]

59. Nichol JW, Koshy ST, Bae H, Hwang CM, Yamanlar S, Khademhosseini A. Biomaterials. 2010; 31:5536. [PubMed: 20417964]

60. Thomas V, Zhang X, Catledge SA, Vohra YK. Biomedical materials (Bristol, England). 2007; 2:224.

61. Li WJ, Laurencin CT, Caterson EJ, Tuan RS, Ko FK. J Biomed Mater Res. 2002; 60:613. [PubMed: 11948520]

62. Kakinoki S, Nakayama M, Moritan T, Yamaoka T. Frontiers in chemistry. 2014; 2:52. [PubMed: 25101261]

63. Swindle-Reilly KE, Paranjape CS, Miller CA. Progress in Biomaterials. 2014; 3:1.

64. McClure MJ, Sell SA, Simpson DG, Walpoth BH, Bowlin GL. Acta biomaterialia. 2010; 6:2422. [PubMed: 20060934]

65. Lee SJ, Yoo JJ, Lim GJ, Atala A, Stitzel J. Journal of biomedical materials research. Part A. 2007; 83:999. [PubMed: 17584890]

66. Han J, Lazarovici P, Pomerantz C, Chen X, Wei Y, Lelkes PI. Biomacromolecules. 2011; 12:399. [PubMed: 21182235]

67. Rnjak-Kovacina J, Wise SG, Li Z, Maitz PK, Young CJ, Wang Y, Weiss AS. Acta biomaterialia. 2012; 8:3714. [PubMed: 22750739] 
68. Stitzel J, Liu J, Lee SJ, Komura M, Berry J, Soker S, Lim G, Van Dyke M, Czerw R, Yoo JJ, Atala A. Biomaterials. 2006; 27:1088. [PubMed: 16131465]

69. Williams DF. Biomaterials. 2008; 29:2941. [PubMed: 18440630]

70. Zhang YZ, Su B, Venugopal J, Ramakrishna S, Lim CT. International journal of nanomedicine. 2007; 2:623. [PubMed: 18203429]

71. Nakagawa S, Pawelek P, Grinnell F. Journal of investigative dermatology. 1989; 93:792. [PubMed: 2584746]

72. Hubbell JA. Nature Biotechnology. 1995; 13:565.

73. Zhang X, Thomas V, Vohra YK. Journal of materials science. Materials in medicine. 2010; 21:541. [PubMed: 19902335]

74. Li M, Mondrinos MJ, Chen X, Gandhi MR, Ko FK, Lelkes PI. Journal of biomedical materials research. Part A. 2006; 79:963. [PubMed: 16948146]

75. Chandy T, Rao GH, Wilson RF, Das GS. Journal of biomaterials applications. 2003; 17:287. [PubMed: 12797421]

76. Sell SA, McClure MJ, Barnes CP, Knapp DC, Walpoth BH, Simpson DG, Bowlin GL. Biomedical materials (Bristol, England). 2006; 1:72.

77. McClure MJ, Simpson DG, Bowlin GL. Journal of the mechanical behavior of biomedical materials. 2012; 10:48. [PubMed: 22520418]

78. Waterhouse A, Wise SG, Ng MK, Weiss AS. Tissue engineering. Part B, Reviews. 2011; 17:93. [PubMed: 21166482] El-Kurdi MS, Hong Y, Stankus JJ, Soletti L, Wagner WR, Vorp DA. Biomaterials. 2008; 29:3213. [PubMed: 18455787]

79. Boland ED, Matthews JA, Pawlowski KJ, Simpson DG, Wnek GE, Bowlin GL. Frontiers in bioscience: a journal and virtual library. 2004; 9:1422. [PubMed: 14977557]

80. Buttafoco L, Kolkman NG, Engbers-Buijtenhuijs P, Poot AA, Dijkstra PJ, Vermes I, Feijen J. Biomaterials. 2006; 27:724. [PubMed: 16111744]

81. Yang, X.; Wang, H. "Creation of vessel-like patches enabled by poly (caprolactone)/collagen/ elastin composite nanofibers". presented at Bioengineering Conference, Proceedings of the 2010 IEEE 36th Annual Northeast; 2010.

82. Sachlos E, Czernuszka J. Eur Cell Mater. 2003; 5:39.

83. Daamen WF, van Moerkerk HT, Hafmans T, Buttafoco L, Poot AA, Veerkamp JH, van Kuppevelt TH. Biomaterials. 2003; 24:4001. [PubMed: 12834595]

84. Vasconcelos A, Gomes AC, Cavaco-Paulo A. Acta biomaterialia. 2012; 8:3049. [PubMed: 22546517]

85. Mercuri J, Addington C, Pascal R 3rd, Gill S, Simionescu D. Journal of biomedical materials research. Part A. 2014

86. Buttafoco L, Engbers - Buijtenhuijs P, Poot A, Dijkstra P, Daamen W, Van Kuppevelt T, Vermes I, Feijen J. Journal of Biomedical Materials Research Part B: Applied Biomaterials. 2006; 77:357.

87. Koens M, Faraj K, Wismans R, Van der Vliet J, Krasznai A, Cuijpers V, Jansen J, Daamen W, Van Kuppevelt T. Acta biomaterialia. 2010; 6:4666. [PubMed: 20619367]

88. Dehghani F, Annabi N. Current Opinion in Biotechnology. 2011; 22:661. [PubMed: 21546240]

89. Annabi N, Fathi A, Mithieux SM, Weiss AS, Dehghani F. The Journal of Supercritical Fluids. $2011 ; 59: 157$.

90. Ji C, Annabi N, Hosseinkhani M, Sivaloganathan S, Dehghani F. Acta biomaterialia. 2012; 8:570. [PubMed: 21996623]

91. Annabi N, Fathi A, Mithieux SM, Martens P, Weiss AS, Dehghani F. Biomaterials. 2011; 32:1517. [PubMed: 21115195]

92. Serban MA, Kluge JA, Laha MM, Kaplan DL. Biomacromolecules. 2010; 11:2230. [PubMed: 20712340]

93. Hu X, Park SH, Gil ES, Xia XX, Weiss AS, Kaplan DL. Biomaterials. 2011; 32:8979. [PubMed: 21872326]

94. Hu X, Tang-Schomer MD, Huang W, Xia XX, Weiss AS, Kaplan DL. Advanced functional materials. 2013; 23:3875. [PubMed: 25093018] 
95. Hu X, Wang X, Rnjak J, Weiss AS, Kaplan DL. Biomaterials. 2010; 31:8121. [PubMed: 20674969]

96. Ghezzi CE, Rnjak - Kovacina J, Weiss AS, Kaplan DL. Israel Journal of Chemistry. 2013; 53:777. [PubMed: 26005219]

97. Trabbic-Carlson K, Meyer DE, Liu L, Piervincenzi R, Nath N, LaBean T, Chilkoti A. Protein Eng. Des. Sel. 2004; 17:57. [PubMed: 14985538]

98. Spezzacatena C, Perri T, Guantieri V, Sandberg LB, Mitts TF, Tamburro AM. Eur. J. Org. Chem. 2002:95.

99. Martino M, Tamburro AM. Biopolymers. 2001; 59:29. [PubMed: 11343278]

100. Swierczewska M, Hajicharalambous CS, Janorkar AV, Megeed Z, Yarmush ML, Rajagopalan P. Acta biomaterialia. 2008; 4:827. [PubMed: 18178532]

101. Flamia R, Zhdan PA, Martino M, Castle JE, Tamburro AM. Biomacromolecules. 2004; 5:1511. [PubMed: 15244472]

102. Ciofani G, Genchi GG, Liakos I, Athanassiou A, Mattoli V, Bandiera A. Acta biomaterialia. 2013; 9:5111. [PubMed: 23085563] Bozzini S, Giuliano L, Altomare L, Petrini P, Bandiera A, Conconi MT, Fare S, Tanzi MC, Mater J. Sci.-Mater. Med. 2011; 22:2641.

103. Meyer DE, Chilkoti A. Biomacromolecules. 2002; 3:357. [PubMed: 11888323]

104. Cappello J, Crissman J, Dorman M, Mikolajczak M, Textor G, Marquet M, Ferrari F. Biotechnol. Prog. 1990; 6:198. [PubMed: 1366613]

105. McGrath KP, Tirrell DA, Kawai M, Mason TL, Fournier MJ. Biotechnol. Prog. 1990; 6:188. [PubMed: 1366612]

106. Meyer DE, Chilkoti A. Nature Biotechnology. 1999; 17:1112.

107. McMillan RA, Lee TAT, Conticello VP. Macromolecules. 1999; 32:3643.

108. McMillan RA, Conticello VP. Macromolecules. 2000; 33:4809.

109. Kurihara H, Morita T, Shinkai M, Nagamune T. Biotechnol. Lett. 2005; 27:665. [PubMed: 15977075]

110. Amiram M, Quiroz FG, Callahan DJ, Chilkoti A. Nature Materials. 2011; 10:141. [PubMed: 21258353]

111. Chow D, Nunalee ML, Lim DW, Simnick AJ, Chilkoti A. Mater. Sci. Eng. R-Rep. 2008; 62:125. [PubMed: 19122836]

112. Christensen T, Amiram M, Dagher S, Trabbic-Carlson K, Shamji MF, Setton LA, Chilkoti A. Protein Science. 2009; 18:1377. [PubMed: 19533768]

113. McDaniel JR, MacKay JA, Quiroz FG, Chilkoti A. Biomacromolecules. 2010; 11:944. [PubMed: 20184309]

114. Rosano GL, Ceccarelli EA. Front. Microbiol. 2014:5. [PubMed: 24523715]

115. Jana S, Deb JK. Appl. Microbiol. Biotechnol. 2014; 98:5787. [PubMed: 24851854] Chow DC, Dreher MR, Trabbic-Carlson K, Chilkoti A. Biotechnol. Prog. 2006; 22:638. [PubMed: 16739944]

116. Angov, E.; Legler, P.; Mease, R. Heterologous Gene Expression in E.coli. Evans, JTC.; Xu, M-Q., editors. Vol. 705. Humana Press; 2011. p. 1

117. Opal, SM. Endoxemia and Endotoxin Shock: Disease, Diagnosis and Therapy. Ronco, C.; Piccinni, P.; Rosner, MH., editors. Vol. 167. Karger; Basel: 2010. p. 14

118. Sallach RE, Conticello VP, Chaikof EL. Biotechnol. Prog. 2009; 25:1810. [PubMed: 19827084]

119. Schipperus R, Teeuwen RLM, Werten MWT, Eggink G, de Wolf FA. Appl. Microbiol. Biotechnol. 2009; 85:293. [PubMed: 19565236]

120. Giddings G, Allison G, Brooks D, Carter A. Nature Biotechnology. 2000; 18:1151.

121. Conley AJ, Joensuu JJ, Jevnikar AM, Menassa R, Brandle JE. Biotechnol. Bioeng. 2009; 103:562. [PubMed: 19266472]

122. Trabbic-Carlson K, Liu L, Kim B, Chilkoti A. Protein Science. 2004; 13:3274. [PubMed: 15557268]

123. Hassouneh W1 CT, Chilkoti A. Current Protocols in Protein Science. 2010 Chapter 6, Unit 611. 
124. Christensen T, Trabbic-Carlson K, Liu WG, Chilkoti A. Analytical Biochemistry. 2007; 360:166. [PubMed: 17084802]

125. Shah M, Hsueh PY, Sun GY, Chang HY, Janib SM, MacKay JA. Protein Science. 2012; 21:743. [PubMed: 22434766]

126. Serrano V, Liu W, Franzen S. Biophys. J. 2007; 93:2429. [PubMed: 17545236]

127. Urry, DW.; Hayes, L.; Luan, CX.; Gowda, DC.; McPherson, D.; Xu, J.; Parker, T. Delta T-tmechanism in the design of self-assembling structures. Springer; Dordrecht: 2001.

128. Urry DW, Luan CH, Parker TM, Gowda DC, Prasad KU, Reid MC, Safavy A. Journal of the American Chemical Society. 1991; 113:4346.

129. Reguera J, Urry DW, Parker TM, McPherson DT, Rodriguez-Cabello JC. Biomacromolecules. 2007; 8:354. [PubMed: 17291058]

130. Rodriguez-Cabello JC, Prieto S, Reguera J, Arias FJ, Ribeiro A. J. Biomater. Sci.-Polym. Ed. 2007; 18:269. [PubMed: 17471765]

131. Meyer DE, Chilkoti A. Biomacromolecules. 2004; 5:846. [PubMed: 15132671]

132. Urry DW, Gowda DC, Parker TM, Luan CH, Reid MC, Harris CM, Pattanaik A, Harris RD. Biopolymers. 1992; 32:1243. [PubMed: 1420991]

133. Cirulis JT, Keeley FW. Biochemistry. 2010; 49:5726. [PubMed: 20527981]

134. Dreher MR, Simnick AJ, Fischer K, Smith RJ, Patel A, Schmidt M, Chilkoti A. Journal of American Chemcial Society. 2008; 130:687.

135. Bellingham CM, Woodhouse KA, Robson P, Rothstein SJ, Keeley FW. Biochim. Biophys. ActaProtein Struct. Molec. Enzym. 2001; 1550:6.Miao M, Bellingham CM, Stahl RJ, Sitarz EE, Lane CJ, Keeley FW. Journal of Biological Chemistry. 2003; 278:48553. [PubMed: 14500713]

136. Kim W, Chaikof EL. Advanced drug delivery reviews. 2010; 62:1468. [PubMed: 20441783]

137. Reguera J, Lagaron JM, Alonso M, Reboto V, Calvo B, Rodriguez-Cabello JC. Macromolecules. $2003 ; 36: 8470$.

138. Garcia-Arevalo C, Pierna M, Girotti A, Arias FJ, Rodriguez-Cabello JC. Soft Matter. 2012; 8:3239.

139. Hern DL, Hubbell JA. Journal of Biomedical Materials Research. 1998; 39:266. [PubMed: 9457557]

140. Punet X, Mauchauffé R, Giannotti MI, Rodríguez-Cabello JC, Sanz F, Engel E, Mateos-Timoneda MA, Planell JA. Biomacromolecules. 2013; 14:2690. [PubMed: 23805782] Kaufmann D, Fiedler A, Junger A, Auernheimer J, Kessler H, Weberskirch R. Macromolecular Bioscience. 2008; 8:577. [PubMed: 18350537]

141. van Eldijk MB, McGann CL, Kiick KL, van Hest JCM. Topics in Current Chemistry. 2012; 310:71. [PubMed: 21826606]

142. Chung HJ, Park TG. Nano Today. 2009; 4:429.

143. Wu XY, Sallach R, Haller CA, Caves JA, Nagapudi K, Conticello VP, Levenston ME, Chaikof EL. Biomacromolecules. 2005; 6:3037. [PubMed: 16283724]

144. Amruthwar SS, Janorkar AV, Mater J. Sci.-Mater. Med. 2012; 23:2903.

145. Wright ER, McMillan RA, Cooper A, Apkarian RP, Conticello VP. Advanced functional materials. 2002; 12:149.

146. Lee J, Macosko CW, Urry DW. Macromolecules. 2001; 34:5968.

147. Lee J, Macosko CW, Urry DW. Macromolecules. 2001; 34:4114.

148. McHale MK, Setton LA, Chilkoti A. Tissue Engineering. 2005; 11:1768. [PubMed: 16411822]

149. Nagapudi K, Brinkman WT, Leisen JE, Huang L, McMillan RA, Apkarian RP, Conticello VP, Chaikof EL. Macromolecules. 2002; 35:1730.Tomatsu I, Peng K, Kros A. Advanced drug delivery reviews. 2011; 63:1257. [PubMed: 21745509]

150. Di Zio K, Tirrell DA. Macromolecules. 2003; 36:1553.

151. Lim DW, Nettles DL, Setton LA, Chilkoti A. Biomacromolecules. 2007; 8:1463. [PubMed: 17411091]

152. McMillan RA, Caran KL, Apkarian RP, Conticello VP. Macromolecules. 1999; 32:9067. 
153. Trabbic-Carlson K, Setton LA, Chilkoti A. Biomacromolecules. 2003; 4:572. [PubMed: 12741772]

154. McMillan RA, Conticello VP. Abstr. Pap. Am. Chem. Soc. 2000; 219:U453.

155. Caplan MR, Moore PN, Zhang SG, Kamm RD, Lauffenburger DA. Biomacromolecules. 2000; 1:627. [PubMed: 11710192]

156. Du A, Zhou B, Xu WW, Yu QJ, Shen Y, Zhang ZH, Shen J, Wu GM. Langmuir. 2013; 29:11208. [PubMed: 23947619]

157. Huang L, McMillan RA, Apkarian RP, Pourdeyhimi B, Conticello VP, Chaikof EL. Macromolecules. 2000; 33:2989.

158. Urry DW LC-H, Harris CM, Parker TM. Protein-based materials. 1997Yan CQ, Pochan DJ. Chemical Society reviews. 2010; 39:3528. [PubMed: 20422104]

159. Martin L, Alonso M, Girotti A, Arias FJ, Rodriguez-Cabello JC. Biomacromolecules. 2009; 10:3015. [PubMed: 19795832]

160. Nagapudi K, Brinkman WT, Leisen J, Thomas BS, Wright ER, Haller C, Wu X, Apkarian RP, Conticello VP, Chaikof EL. Macromolecules. 2005; 38:345.

161. Partridge SM, Davis HF, Adair GS. Biochemical Journal. 1955; 61:11. [PubMed: 13260170]

162. Lin C-C, Metters AT. Advanced drug delivery reviews. 2006; 58:1379. [PubMed: 17081649]

163. Ruiz - Garcia A, Bermejo M, Moss A, Casabo VG. Journal of pharmaceutical sciences. 2008; 97:654. [PubMed: 17630642]

164. Torchilin VP, Lukyanov AN. Drug Discovery Today. 2003; 8:259. [PubMed: 12623240]

165. Gref R, Minamitake Y, Peracchia MT, Trubetskoy V, Torchilin V, Langer R. Science. 1994; 263:1600. [PubMed: 8128245] Kwon GS, Okano T. Pharmaceutical Research. 1999; 16:597. [PubMed: 10349998] Wright ER, Conticello VP. Advanced drug delivery reviews. 2002; 54:1057. [PubMed: 12384307]

166. Asai D, Xu D, Liu W, Garcia Quiroz F, Callahan DJ, Zalutsky MR, Craig SL, Chilkoti A. Biomaterials. 2012; 33:5451. [PubMed: 22538198]

167. Xu D, Asai D, Chilkoti A, Craig SL. Biomacromolecules. 2012; 13:2315. [PubMed: 22789001]

168. Shah M, Hsueh PY, Sun G, Chang HY, Janib SM, MacKay JA. Protein science : a publication of the Protein Society. 2012; 21:743. [PubMed: 22434766]

169. Betre H, Liu W, Zalutsky MR, Chilkoti A, Kraus VB, Setton LA. Journal of Controlled Release. 2006; 115:175. [PubMed: 16959360]

170. Betre, H.; Chilkoti, A.; Setton, LA.; Ieee, I. Second Joint Embs-Bmes Conference 2002, Vols 1-3, Conference Proceedings: Bioengineering - Integrative Methodologies, New Technologies. Ieee; 2002. p. 829

171. Kim S, Kim J-H, Jeon O, Kwon IC, Park K. European Journal of Pharmaceutics and Biopharmaceutics. 2009; 71:420. [PubMed: 18977434] Hoffman AS. Journal of Controlled Release. 2008; 132:153. [PubMed: 18817820]

172. Shamji MF, Whitlatch L, Friedman AH, Richardson WJ, Chilkoti A, Setton LA. Spine. 2008; 33:748. [PubMed: 18379401] Sinclair SM, Bhattacharyya J, McDaniel JR, Gooden DM, Gopalaswamy R, Chilkoti A, Setton LA. Journal of Controlled Release. 2013; 171:38. [PubMed: 23830979]

173. Bieth JG. Journal de la Societe de biologie. 2001; 195:173. [PubMed: 11723830] Chan CH, Ip MSM, Shum DKY. Faseb Journal. 2005; 19:A493.Demkow U, van Overveld FJ. European Journal of Medical Research. 2010; 15:27. [PubMed: 21147616] Hornebeck W, Floresdelgado G, Robert L. Boccalon H. Vascular Medicine. 1993; 1018:137.Morimoto T, Yamasaki M, Nakata K, Tsuji M, Nakamura H. Journal of Endodontics. 2008; 34:1072. [PubMed: 18718368]

174. Bandiera A, Markulin A, Corich L, Vita F, Borrelli V. Biomacromolecules. 2014; 15:416. [PubMed: 24358962]

175. Adams SB, Shamji MF, Nettles DL, Hwang P, Setton LA. Journal of Biomedical Materials Research Part B: Applied Biomaterials. 2009; 90B:67.

176. Bessa PC, Machado R, Nürnberger S, Dopler D, Banerjee A, Cunha AM, Rodríguez-Cabello JC, Redl H, van Griensven M, Reis RL, Casal M. Journal of Controlled Release. 2010; 142:312. [PubMed: 19913578] 
177. Wu Y, MacKay JA, McDaniel JR, Chilkoti A, Clark RL. Biomacromolecules. 2008; 10:19. [PubMed: 19072041]

178. Urry DW, Harris RD, Prasad KU. Journal of the American Chemical Society. 1988; 110:3303.Lee TAT, Cooper A, Apkarian RP, Conticello VP. Advanced Materials. 2000; 12:1105.

179. Kim W, Thevenot J, Ibarboure E, Lecommandoux S, Chaikof EL. Angewandte ChemieInternational Edition. 2010; 49:4257.

180. Koo AN, Lee HJ, Kim SE, Chang JH, Park C, Kim C, Park JH, Lee SC. Chemical Communications. 2008:6570. [PubMed: 19057782]

181. Lai TC, Cho H, Kwon GS. Polymer Chemistry. 2014; 5:1650.Thambi T, Deepagan VG, Ko H, Suh YD, Yi G-R, Lee JY, Lee DS, Park JH. Polymer Chemistry. 2014; 5:4627.Gao L, Luo Q, Wang Y, Du H, Li X, Shen Z, Zhu W. RSC Advances. 2014; 4:4177.

182. Takakura Y, Fujita T, Hashida M, Sezaki H. Pharmaceutical Research. 1990; 7:339. [PubMed: 1694582]

183. Cassidy J, Duncan R, Morrison GJ, Strohalm J, Plocova D, Kopecek J, Kaye SB. Biochemical Pharmacology. 1989; 38:875. [PubMed: 2930589] Maeda H, Seymour LW, Miyamoto Y. Bioconjugate Chemistry. 1992; 3:351. [PubMed: 1420435]

184. Jain RK. Scientific American. 1994; 271:58. [PubMed: 8066425]

185. Fessenden P, Lee ER, Anderson TL, Strohbehn JW, Meyer JL, Samulski TV, Marmor JB. Biomedical Engineering, IEEE Transactions on 1984, BME-31. :126.Jones E, Thrall D, Dewhirst MW, Vujaskovic Z. International Journal of Hyperthermia. 2006; 22:247. [PubMed: 16754346]

186. Bidwell Iii GL, Raucher D. Advanced drug delivery reviews. 2010; 62:1486. [PubMed: 20478348]

187. Feyerabend T, Steeves R, Wiedemann GJ, Richter E, Robins HI. Anticancer research. 1997; 17:2895. [PubMed: 9329557] Issels RD. Recent results in cancer research. Fortschritte der Krebsforschung. Progres dans les recherches sur le cancer. 1995; 138:81. [PubMed: 7899701]

188. Meyer DE, Kong GA, Dewhirst MW, Zalutsky MR, Chilkoti A. Cancer Research. 2001; 61:1548. [PubMed: 11245464]

189. Dreher MR, Simnick AJ, Fischer K, Smith RJ, Patel A, Schmidt M, Chilkoti A. Journal of the American Chemical Society. 2007; 130:687. [PubMed: 18085778]

190. Draeger LJ, Mullen GP. Journal of Biological Chemistry. 1994; 269:1785. [PubMed: 8294427]

191. Bidwell GL, Raucher D. Molecular Cancer Therapeutics. 2005; 4:1076. [PubMed: 16020665]

192. Van Blitterswijk, C., editor. Tissue Engineering. Academic Press; Burlington, MA.: 2008.

193. Annabi N, Tamayol A, Uquillas JA, Akbari M, Bertassoni LE, Cha C, Camci-Unal G, Dokmeci MR, Peppas NA, Khademhosseini A. Advanced Materials. 2014; 26:85. [PubMed: 24741694] Cai L, Heilshorn SC. Acta biomaterialia. 2014; 10:1751. [PubMed: 24365704] Lutolf MP. Integrative Biology. 2009; 1:235. [PubMed: 20023734] Cittadella Vigodarzere G, Mantero S. Frontiers in Physiology. 2014:5. [PubMed: 24478718] Moroni L, de Wijn JR, van Blitterswijk CA. Journal of biomaterials science. Polymer edition. 2008; 19:543. [PubMed: 18419938]

194. Betre H, Setton LA, Meyer DE, Chilkoti A. Biomacromolecules. 2002; 3:910. [PubMed: 12217035]

195. Betre H, Ong SR, Guilak F, Chilkoti A, Fermor B, Setton LA. Biomaterials. 2006; $27: 91$. [PubMed: 16023192]

196. Setton LA, Mow VC, Howell DS. Journal of Orthopaedic Research. 1995; 13:473. [PubMed: 7674064]

197. Lorand L, Graham RM. Nature Reviews Molecular Cell Biology. 2003; 4:140. [PubMed: 12563291]

198. Lim DW, Nettles DL, Setton LA, Chilkoti A. Biomacromolecules. 2008; 9:222. [PubMed: 18163573]

199. Nettles DL, Kitaoka K, Hanson NA, Flahiff CM, Mata BA, Hsu EW, Chilkoti A, Setton LA. Tissue engineering. Part A. 2008; 14:1133. [PubMed: 18433311]

200. Nettles DL, Haider MA, Chilkoti A, Setton LA. Tissue engineering. Part A. 2010; 16:11. [PubMed: 19754250] 
201. Greisler HP. Archives of Surgery. 1982; 117:1425. [PubMed: 6291492] Melchiorri AJ, Hibino N, Brandes ZR, Jonas RA, Fisher JP. Journal of Biomedical Materials Research Part A. 2014; 102:1972. [PubMed: 23852776] Zhao J, Liu LQ, Wei J, Ma DY, Geng WX, Yan XR, Zhu J, Du HC, Liu Y, Li LW, Chen FL. Artificial Organs. 2012; 36:93. [PubMed: 21790675]

202. Nicol A, Gowda DC, Urry DW. Journal of Biomedical Materials Research. 1992; 26:393. [PubMed: 1613028]

203. Long MM, King VJ, Prasad KU, Freeman BA, Urry DW. Journal of Cellular Physiology. 1989; 140:512. [PubMed: 2476449]

204. Urry DW. Biopolymers. 1998; 47:167.

205. Heilshorn SC, DiZio KA, Welsh ER, Tirrell DA. Biomaterials. 2003; 24:4245. [PubMed: 12853256] Heilshorn SC, Liu JC, Tirrell DA. Biomacromolecules. 2004; 6:318. [PubMed: 15638535]

206. Welsh ER, Tirrell DA. Biomacromolecules. 2000; 1:23. [PubMed: 11709838]

207. Nowatzki PJ, Tirrell DA. Biomaterials. 2004; 25:1261. [PubMed: 14643600]

208. Martínez-Osorio H, Juárez-Campo M, Diebold Y, Girotti A, Alonso M, Arias FJ, RodríguezCabello JC, García-Vázquez C, Calonge M. Current Eye Research. 2009; 34:48. [PubMed: 19172470]

209. Prieto S, Shkilnyy A, Rumplasch C, Ribeiro A, Arias FJ, Rodríguez-Cabello JC, Taubert A. Biomacromolecules. 2011; 12:1480. [PubMed: 21438535]

210. Tejeda-Montes E, Smith KH, Poch M, López-Bosque MJ, Martín L, Alonso M, Engel E, Mata A. Acta biomaterialia. 2012; 8:998. [PubMed: 21945830]

211. Tejeda-Montes E, Klymov A, Nejadnik MR, Alonso M, Rodriguez-Cabello JC, Walboomers XF, Mata A. Biomaterials. 2014; 35:8339. [PubMed: 24996755]

212. Lampe KJ, Antaris AL, Heilshorn SC. Acta biomaterialia. 2013; 9:5590. [PubMed: 23128159]

213. Xia X-X, Xu Q, Hu X, Qin G, Kaplan DL. Biomacromolecules. 2011; 12:3844. [PubMed: 21955178]

214. van Eldijk MB, Smits FCM, Vermue N, Debets MF, Schoffelen S, van Hest JCM. Biomacromolecules. 2014; 15:2751. [PubMed: 24945908]

215. MacKay JA, Chen M, McDaniel JR, Liu W, Simnick AJ, Chilkoti A. Nature Materials. 2009; 8:993. [PubMed: 19898461]

216. Koria P, Yagi H, Kitagawa Y, Megeed Z, Nahmias Y, Sheridan R, Yarmush ML. Proceedings of the National Academy of Sciences of the United States of America. 2011; 108:1034. [PubMed: 21193639]

217. MacEwan SR, Chilkoti A. Nano Letters. 2012; 12:3322. [PubMed: 22625178]

218. McDaniel JR, Bhattacharyya J, Vargo KB, Hassouneh W, Hammer DA, Chilkoti A. Angewandte Chemie International Edition in English. 2013; 52:1683.

219. Park SM, Cha JM, Nam J, Kim MS, Park SJ, Park ES, Lee H, Kim HR. PLOS One. 2014:9.

220. Costa RR, Custódio CA, Arias FJ, Rodríguez-Cabello JC, Mano JF. Nanomedicine: Nanotechnology, Biology and Medicine. 2013; 9:895.

221. MacEwan SR, Chilkoti A. Journal of Controlled Release. 2014; 190:314. [PubMed: 24979207]

222. McDaniel JR, Weitzhandler I, Prevost S, Vargo KB, Appavou M-S, Hammer DA, Gradzielski M, Chilkoti A. Nano Letters. 2014

223. Meyer DE, Chilkoti A. Biomacromolecules. 2004; 5:846. [PubMed: 15132671]

224. Johnson NR, Wang Y. Expert Opinion on Drug Delivery. 2014; 0:1.

225. González de Torre I, Quintanilla L, Pinedo-Martín G, Alonso M, Rodríguez-Cabello JC. ACS Applied Materials \& Interfaces. 2014; 6:14509. [PubMed: 25068707]

226. Park SM, Kim MS, Park SJ, Park ES, Choi KS, Kim YS, Kim HR. Journal of Controlled Release. 2013; 170:373. [PubMed: 23770213]

227. Nath N, Chilkoti A. Journal of the American Chemical Society. 2001; 123:8197. [PubMed: 11516269]

228. Kojima C, Irie K. Biopolymers. 2013; 100:714. [PubMed: 23893507] Koga T, Iimura M, Higashi N. Macromolecular Bioscience. 2012; 12:1043. [PubMed: 22344970] 
229. Liu W, Dreher MR, Furgeson DY, Peixoto KV, Yuan H, Zalutsky MR, Chilkoti A. Journal of Controlled Release. 2006; 116:170. [PubMed: 16919353]

230. Chen TH, Bae Y, Furgeson DY. Pharmaceutical Research. 2008; 25:683. [PubMed: 17762916]

231. Shah M, Hsueh Y-S, Sun G, Chang HY, Janib SM, MacKay JA. Protein Science. 2012; 21:743. [PubMed: 22434766]

232. Cai L, Dinh CB, Heilshorn SC. Biomaterials Science. 2014; 2:757. [PubMed: 24729868]

233. Garcia Y, Hemantkumar N, Collighan R, Griffin M, Rodríguez-Cabello JC, Pandit A. Tissue Engineering Part A. 2009; 15:887. [PubMed: 18976154]

234. Shi P, Aluri S, Lin Y-A, Shah M, Edman M, Dhandhukia J, Cui H, MacKay JA. Journal of Controlled Release. 2013; 171:330. [PubMed: 23714121]

235. Hsueh Y-S, Savitha S, Sadhasivam S, Lin F-H, Shieh M-J. Materials Science and Engineering: C. 2014; 38:119. [PubMed: 24656360]

236. Amruthwar SS, Janorkar AV. Dental Materials. 2013; 29:211. [PubMed: 23127995]

237. Anderson TR, Marquart ME, Janorkar AV. Journal of Biomedical Materials Research Part A. 2014 n/a.

238. Bonzon N, Carrat X, Deminiere C, Daculsi G, Lefebvre F, Rabaud M. Biomaterials. 1995; 16:881. [PubMed: 8527605]

239. Wang H, Cai L, Paul A, Enejder A, Heilshorn SC. Biomacromolecules. 2014; 15:3421. [PubMed: 25111283]

240. Ravi S, Caves JM, Martinez AW, Haller CA, Chaikof EL. Journal of Biomedical Materials Research Part A. 2013; 101A:1915. [PubMed: 23225639]

241. Li Y, Chen X, Ribeiro AJ, Jensen ED, Holmberg KV, Rodriguez-Cabello JC, Aparicio C. Advanced Healthcare Materials. 2014 n/a.

242. Kinikoglu B, Rodríguez-Cabello J, Damour O, Hasirci V. J Mater Sci: Mater Med. 2011; 22:1541. [PubMed: 21505829]

243. Boccafoschi F, Ramella M, Sibillano T, De Caro L, Giannini C, Comparelli R, Bandiera A, Cannas M. Journal of Biomedical Materials Research Part A. 2014 n/a.

244. Moss IL, Gordon L, Woodhouse KA, Whyne CM, Yee AJ. Spine. 2011; 36:1022. [PubMed: 21150701]

245. Wheeler T, Sbravati N, Janorkar A. Annals of biomedical engineering. 2013; 41:2042. [PubMed: 23677640]

246. Khatiwala CB, Peyton SR, Putnam AJ. American Journal of Physiology - Cell Physiology. 2006; 290:1640.

247. Yannas IV, Lee E, Orgill DP, Skrabut EM, Murphy GF. Proceedings of the National Academy of Sciences of the United States of America. 1989; 86:933. [PubMed: 2915988]

248. Kinikoglu B, Auxenfans C, Pierrillas P, Justin V, Breton P, Burillon C, Hasirci V, Damour O. Biomaterials. 2009; 30:6418. [PubMed: 19698987]

249. Blit PH, Battiston KG, Yang M, Paul Santerre J, Woodhouse KA. Acta biomaterialia. 2012; 8:2493. [PubMed: 22459513]

250. Fernández-Colino A, Arias FJ, Alonso M, Rodríguez-Cabello JC. Biomacromolecules. 2014

251. Yannas IV, Burke JF. Journal of Biomedical Materials Research Part A. 1980; 14:65.

252. Leckie AE, Akens MK, Woodhouse KA, Yee AJ, Whyne CM. Spine. 2012:37.

253. Wang E, Lee S-H, Lee S-W. Biomacromolecules. 2011; 12:672. [PubMed: 21218767]

254. Drury JL, Mooney DJ. Biomaterials. 2003; 24:4337. [PubMed: 12922147]

255. Daamen WF, Nillesen STM, Wismans RG, Reinhardt DP, Hafmans T, Veerkamp JH, van Kuppevelt TH. Tissue Engineering Part A. 2008; 14:349. [PubMed: 18333787]

256. Martin P. Science. 1997; 276:75. [PubMed: 9082989]

257. Daamen WF, Veerkamp JH, van Hest JCM, van Kuppevelt TH. Biomaterials. 2007; 28:4378. [PubMed: 17631957]

258. Machado R, Costa A. d. Sencadas V, Garcia-Arévalo C, Costa CM, Padrão J, Gomes A, Lanceros-Méndez S, Rodríguez-Cabello JC, Casal M. Biomedical Materials. 2013; 8:065009. [PubMed: 24287397] 
259. Zeng L, Jiang L, Teng W, Cappello J, Zohar Y, Wu X. Macromolecular Rapid Communications. 2014; 35:1273. [PubMed: 24798978]

260. Hwang W, Kim B-H, Dandu R, Cappello J, Ghandehari H, Seog J. Langmuir. 2009; 25:12682. [PubMed: 19803470]

261. Qiu W, Teng W, Cappello J, Wu X. Biomacromolecules. 2009; 10:602. [PubMed: 19186950]

262. Johnson S, Ko YK, Varongchayakul N, Lee S, Cappello J, Ghandehari H, Lee SB, Solares SD, Seog J. Chemical Communications. 2012; 48:10654. [PubMed: 23000884]

263. Abrams GA, Goodman SL, Nealey PF, Franco M, Murphy CJ. Cell and Tissue Research. 2000; 299:39. [PubMed: 10654068]

264. Nagarsekar A, Crissman J, Crissman M, Ferrari F, Cappello J, Ghandehari H. Journal of Biomedical Materials Research. 2002; 62:195. [PubMed: 12209939] Nagarsekar A, Crissman J, Crissman M, Ferrari F, Cappello J, Ghandehari H. Biomacromolecules. 2003; 4:602. [PubMed: 12741775]

265. Caves JM, Cui W, Wen J, Kumar VA, Haller CA, Chaikof EL. Biomaterials. 2011; 32:5371. [PubMed: 21550111]

266. Barbosa JS, Costa RR, Testera AM, Alonso M, Rodríguez-Cabello JC, Mano JF. Nanoscale Research Letters. 2009; 4:1247. [PubMed: 20596391]

267. Costa RR, Testera AM, Arias FJ, Rodríguez-Cabello JC, Mano JF. The Journal of Physical Chemistry B. 2013; 117:6839. [PubMed: 23662646]

268. Teng W, Huang Y, Cappello J, Wu X. The Journal of Physical Chemistry B. 2011; 115:1608. [PubMed: 21288001] Teng W, Cappello J, Wu X. Biomacromolecules. 2009; 10:3028. [PubMed: 19788307]

269. Caves JM, Kumar VA, Martinez AW, Kim J, Ripberger CM, Haller CA, Chaikof EL. Biomaterials. 2010; 31:7175. [PubMed: 20584549]

270. Qiu W, Huang Y, Teng W, Cohn CM, Cappello J, Wu X. Biomacromolecules. 2010; 11:3219. [PubMed: 21058633]

271. L'heureux N, Pâquet S, Labbé R, Germain L, Auger FA. The FASEB Journal. 1998; 12:47. [PubMed: 9438410] Kubo H, Shimizu T, Yamato M, Fujimoto T, Okano T. Biomaterials. 2007; 28:3508. [PubMed: 17482255]

272. Teng W, Cappello J, Wu X. Journal of Controlled Release. 2011; 156:186. [PubMed: 21839125]

273. Pezowicz CA, Robertson PA, Broom ND. Journal of Anatomy. 2006; 208:317. [PubMed: 16533315] Glagov S, Vito R, Giddens DP, Zarins CK. Journal of Hypertension. Supplement. 1992; 10:S101.Axer H, Keyserlingk D. G. v. Prescher A. Journal of Surgical Research. 2001; 96:127. [PubMed: 11181006]

274. McKenna KA, Hinds MT, Sarao RC, Wu PC, Maslen CL, Glanville RW, Babcock D, Gregory KW. Acta biomaterialia. 2012; 8:225. [PubMed: 21846510]

275. Mithieux SM, Wise SG, Raftery MJ, Starcher B, Weiss AS. Journal of structural biology. 2005; 149:282. [PubMed: 15721582]

276. Leach JB, Wolinsky JB, Stone PJ, Wong JY. Acta biomaterialia. 2005; 1:155. [PubMed: 16701792]

277. Liu H, Wise SG, Rnjak-Kovacina J, Kaplan DL, Bilek MM, Weiss AS, Fei J, Bao S. Biomaterials. 2014; 35:5138. [PubMed: 24702962]

278. Vieth S, Bellingham CM, Keeley EW, Hodge SM, Rousseau D. Biopolymers. 2007; 85:199. [PubMed: 17066474]

279. Miao M, Sitarz E, Bellingham CM, Won E, Muiznieks LD, Keeley FW. Biopolymers. 2013; 99:392. [PubMed: 23529691]

280. Iatridis JC, Setton LA, Weidenbaum M, Mow VC. J. Orthop. Res. 1997; 15:318. [PubMed: 9167638]

281. Setton LA, Mow VC, Howell DS. J. Orthop. Res. 1995; 13:473. [PubMed: 7674064]

282. Gosline J, Lillie M, Carrington E, Guerette P, Ortlepp C, Savage K. Philosophical Transactions of the Royal Society of London Series B-Biological Sciences. 2002; 357:121.Aaron BB, Gosline JM. Biopolymers. 1981; 20:1247. 
283. Bellingham CM, Lillie MA, Gosline JM, Wright GM, Starcher BC, Bailey AJ, Woodhouse KA, Keeley FW. Biopolymers. 2003; 70:445. [PubMed: 14648756] 


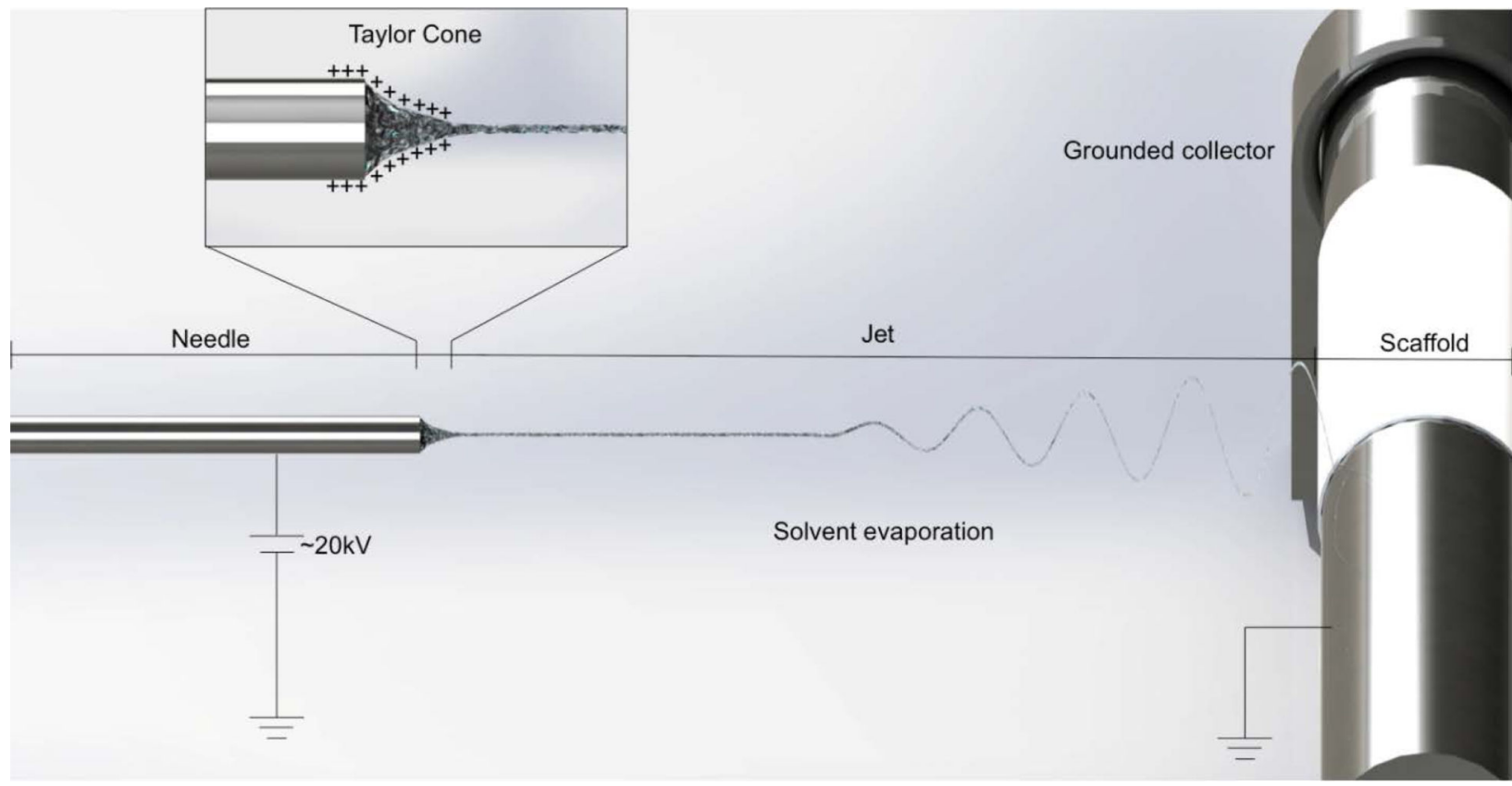

Figure 1.

Schematic diagram of a typical electrospinning setup used to produce fibrous elastin materials. 


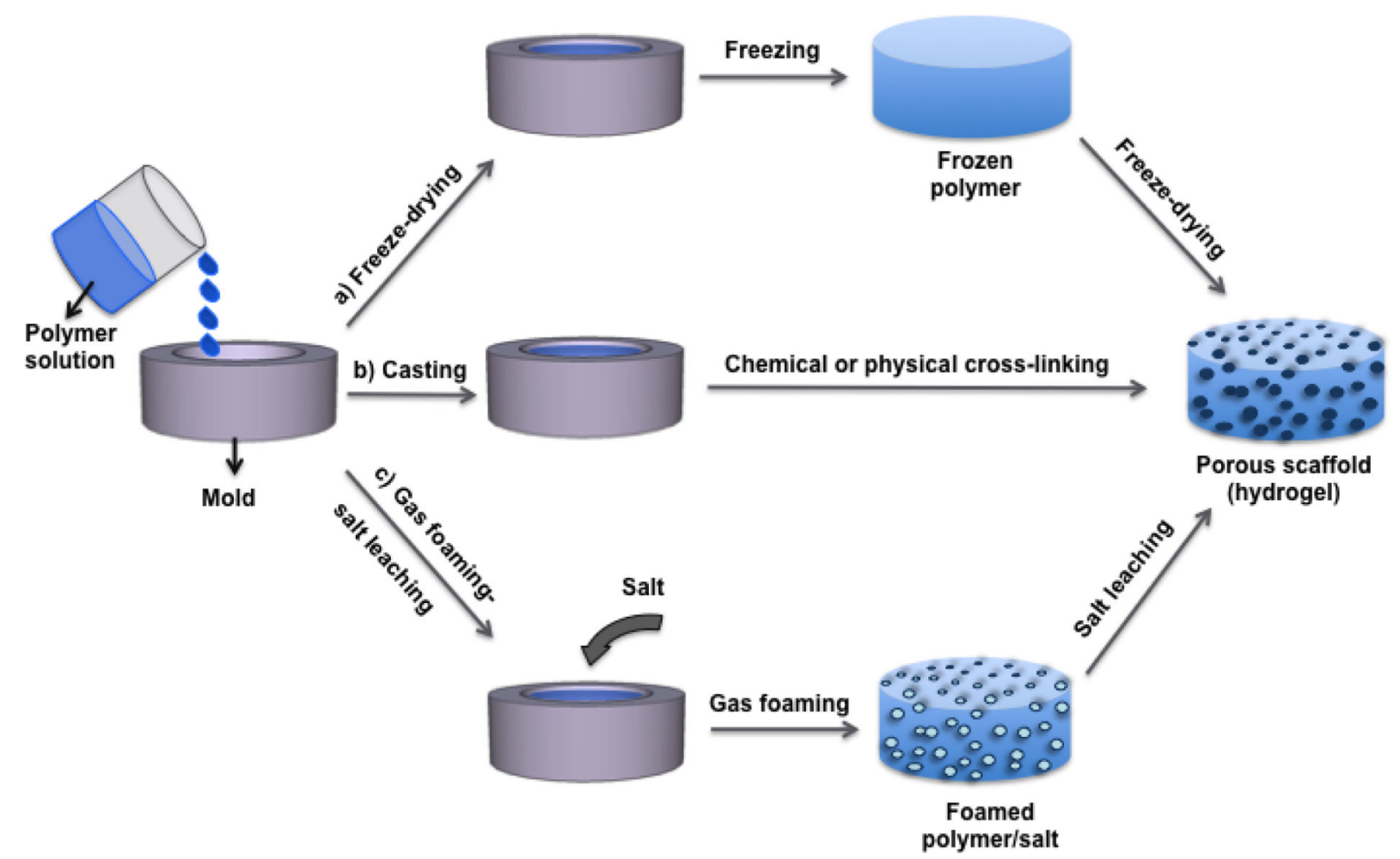

Figure 2.

Schematic diagram showing various paths to fabricate elastin-based hydrogels. The single/ blended polymer solution is poured into a mold, and a) freeze-dried, b) chemically or physically cross-linked to form a hydrogel. C) The polymer solution was mixed with salt and poured in a mold to cast. The disc was placed in in a high pressure vessel for gas foaming by dense gas, then placed in water to leach out the salt, so forming a porous scaffold. 
A

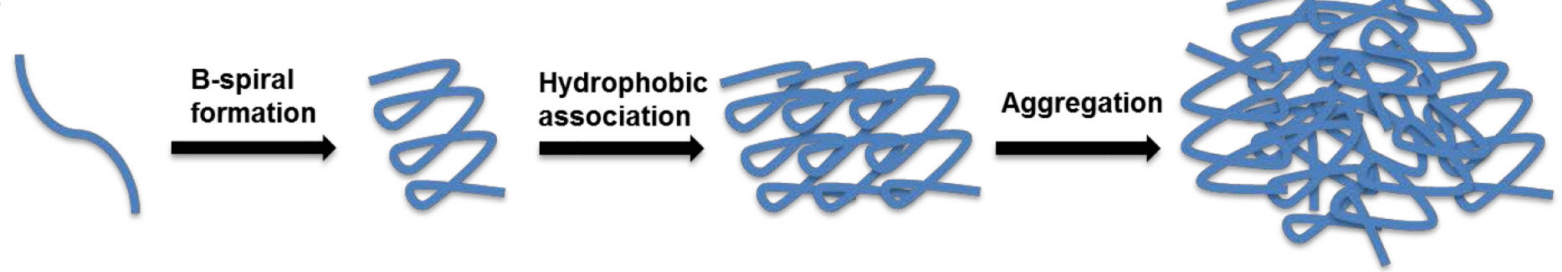

B

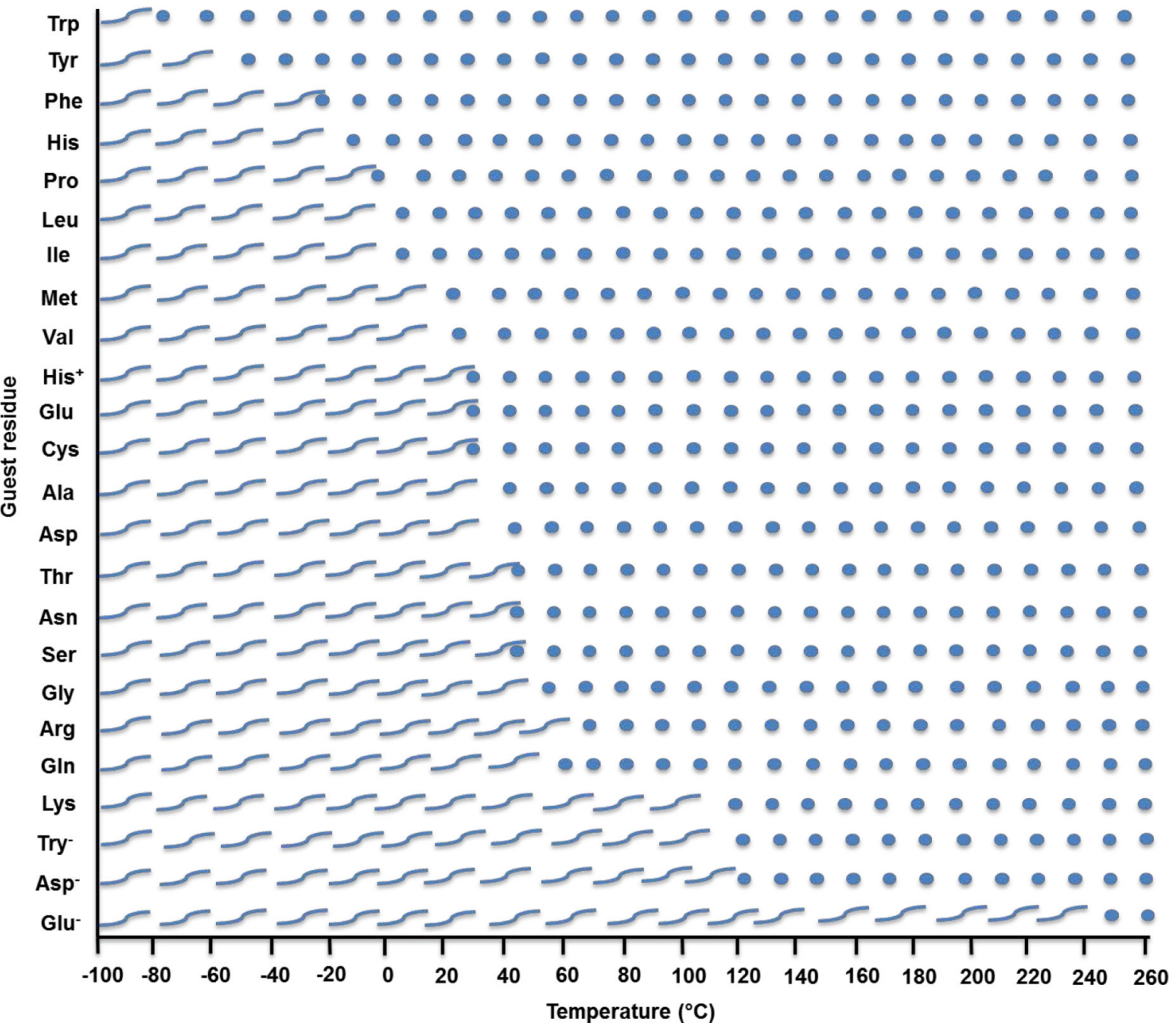

Figure 3.

A) The mechanism of ELP transition from a soluble state to a coacervated state at the transition temperature. ELP monomers form $\beta$-spirals which are stabilized by hydrophobic interactions. The polypeptide chains then associate into larger aggregates. B) Effect of the guest residue $X$ on the coacervation temperature of $[\mathrm{VPG} X \mathrm{G}]_{\mathrm{n}}$ ELPs. Wavy lines represent ELPs in soluble form below their inverse transition temperatures, while circles represent coacervated ELPs. 


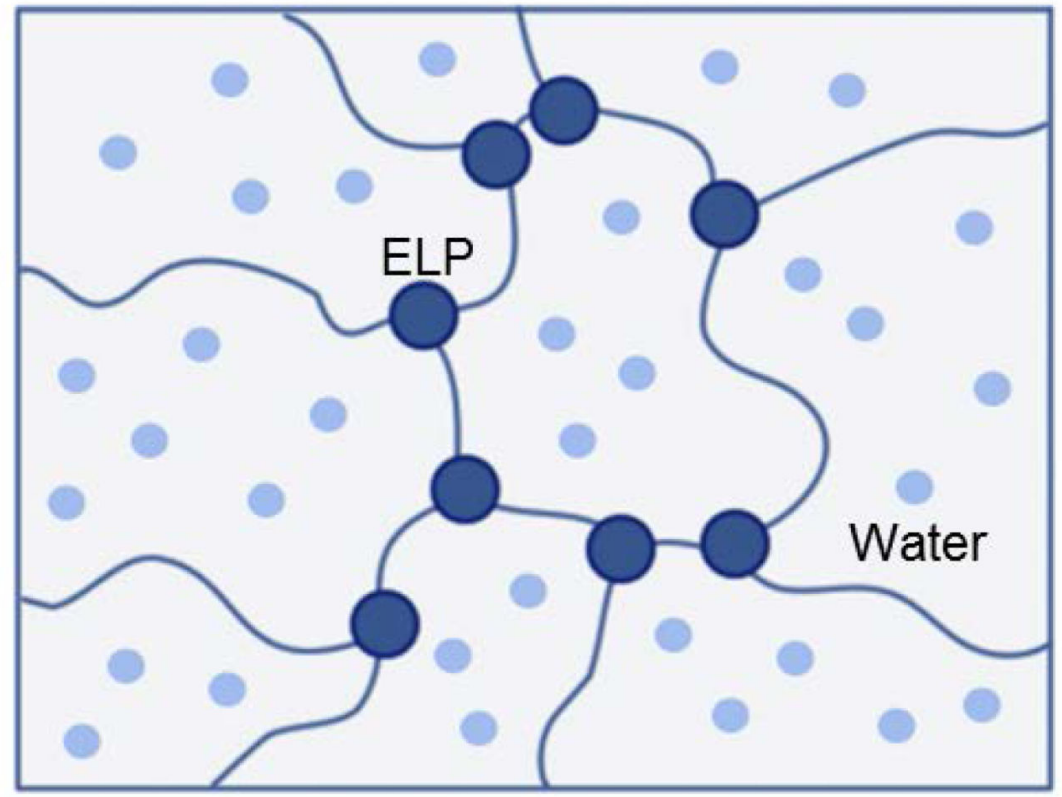

Heating

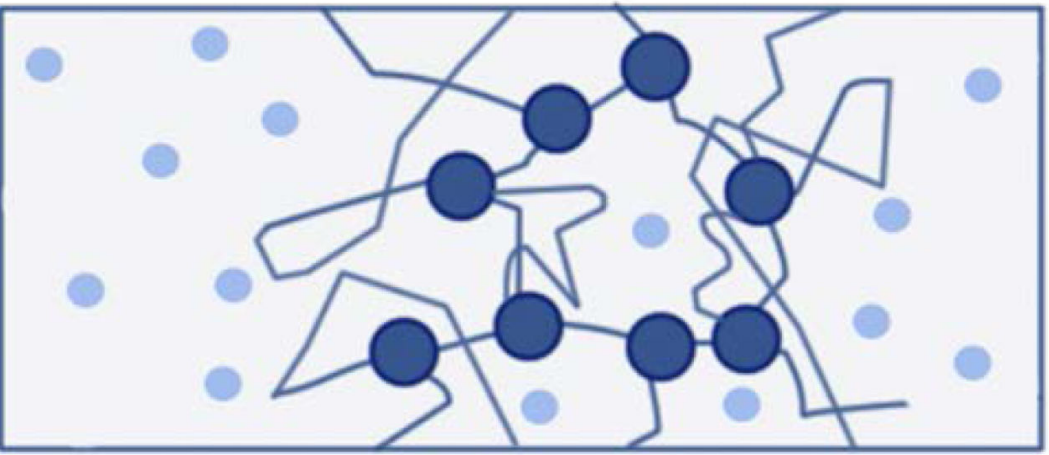

Figure 4.

Schematic diagram of water loss arising from the contraction of ELP hydrogels upon a temperature increase. At $7{ }^{\circ} \mathrm{C}$, the ELP component within the hydrogel is fully extended, with water molecules scattered around the ELP segments. Once the temperature is raised to $37^{\circ} \mathrm{C}$, the gels contract, allowing the escape of water molecules. 
A
$[\mathrm{A}]-[\mathrm{X}]-[\mathrm{B}]$
unon
$A=$ VPGEG $[(V P G V G)(V P G E G)(V P G V G)(V P G E G)(V P G V G)]_{10}$
$B=\left[(I P G V G)_{2} V P G Y G(I P G V G)_{2}\right]_{12} V P G Y G$
$X=$ CCCCGGG

B

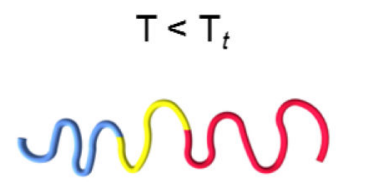

\section{$\Delta T$}

$\mathrm{T}>\mathrm{T}_{t}$

C

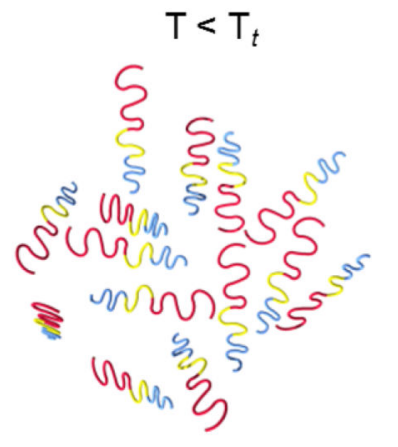

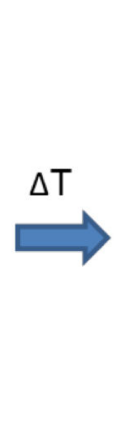
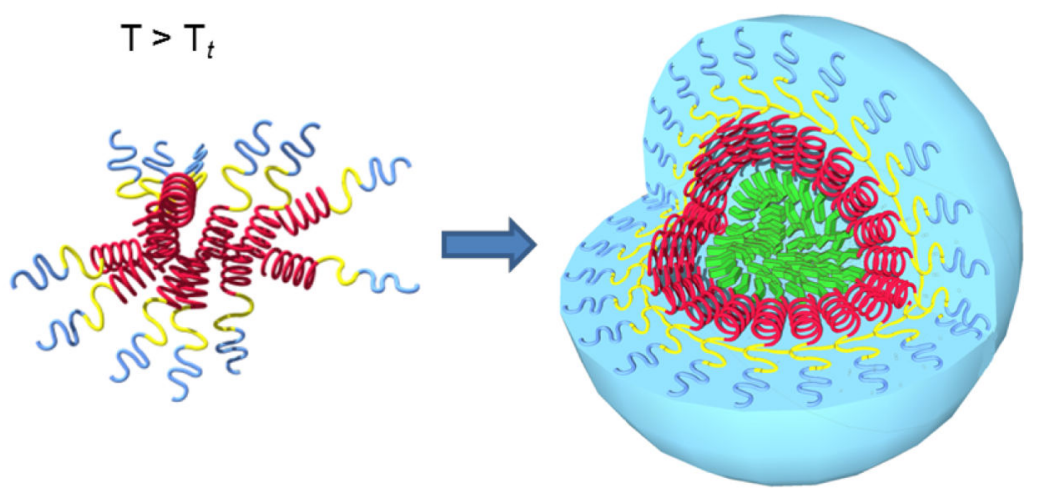

Figure 5.

Formation of ELP micellar structures. A) Schematic diagram a cysteine-enhanced amphiphilic ELP diblock showing the hydrophilic (A, blue), hydrophobic (B, red), and cysteine-enriched inter-block (X, yellow) regions. Example amino acid sequences for each block are indicated. B) Structural change in ELPs during self-assembly, characterized by the folding of the hydrophobic block into a $\beta$-spiral above the $\mathrm{T}_{t}$. C) Below the $\mathrm{T}_{t}$, the unfolded ELPs are soluble. Above the $\mathrm{T}_{t}$, ELPs aggregate and form micelles if the critical ELP concentration is reached. The micelles are stabilized by disulfide bridges between cysteine residues (yellow). Micelles can trap hydrophobic drug molecules (green) within the apolar core. 


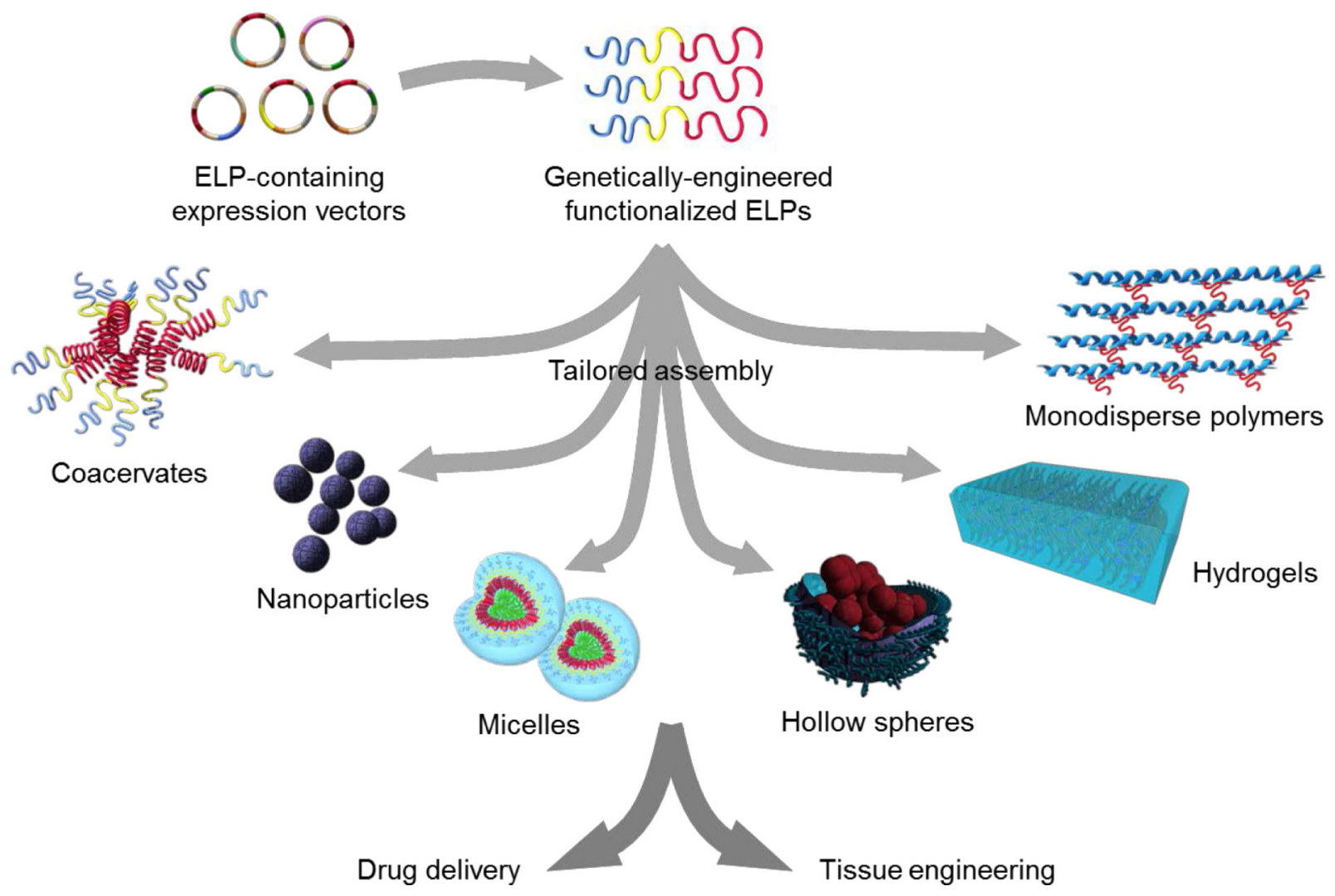

Figure 6.

Production of ELPs by genetic engineering allows for precise sequence control and rational design of tunable properties. Fabrication techniques permit the modulation of temperature, $\mathrm{pH}$, ionic strength, solvent, and cross-linking agent, and enable the incorporation of other functional molecules to produce a range of ELP-based materials such as coacervates, nanoparticles, micelles, hollow spheres and hydrogels. These materials have diverse applications in drug delivery and tissue engineering. 
A

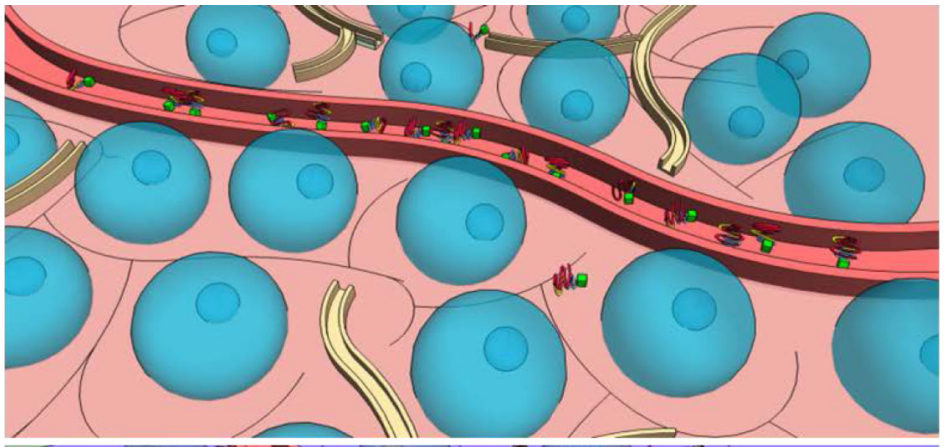

B

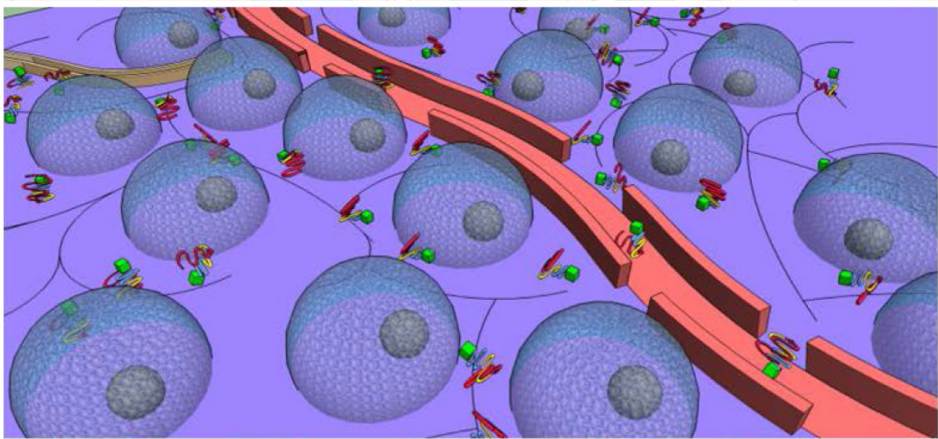

C

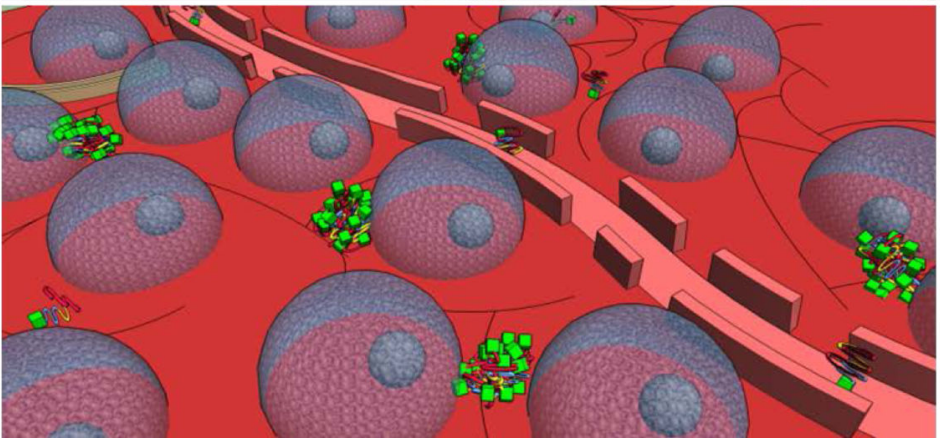

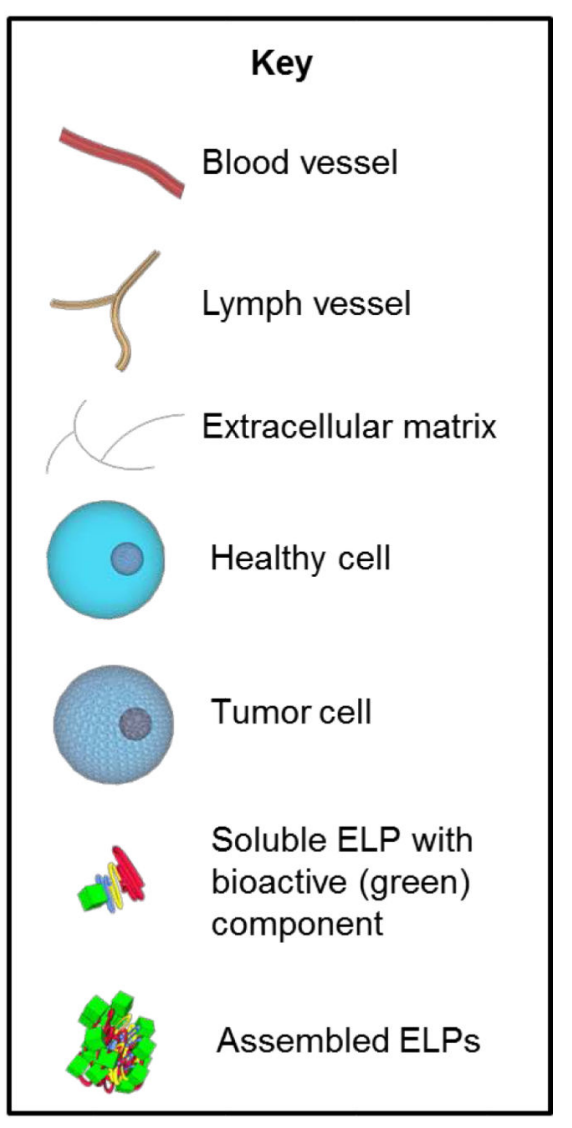

Figure 7.

Targeted assembly of drug-carrying ELPs in tumor tissues. A) Blood vessels in healthy tissues retain soluble, large-molecule ELPs, while those that leak into the extracellular matrix are quickly drained by lymph vessels. B) Tumor tissues tend to be characterized by leaky blood vessels and scarce lymphatic drainage. Consequently, a high concentration of soluble ELPs build up in the tumor environment. C) Localized hyperthermia of tumor tissues by focused ultrasound, microwave or infrared radiation increases the leakiness of blood vessels and accumulation of ELPs above a critical concentration. The hyperthermic tumor environment induces ELP coacervation to preferentially present the bioactive moieties on the microspherule surface. 


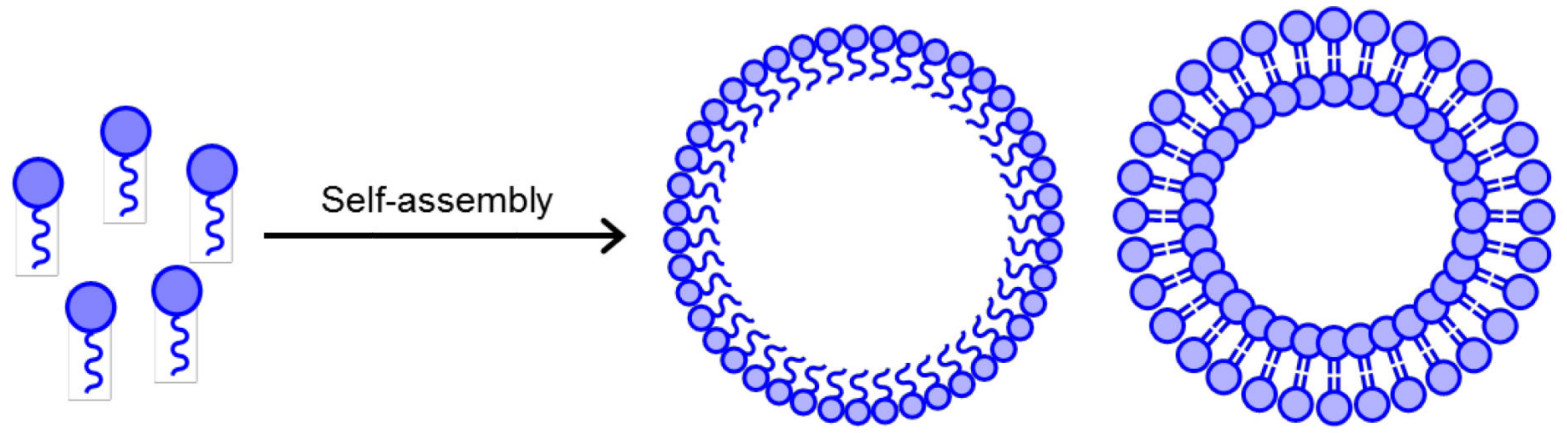

ELP-conjugate

Composite ELP-based micelles
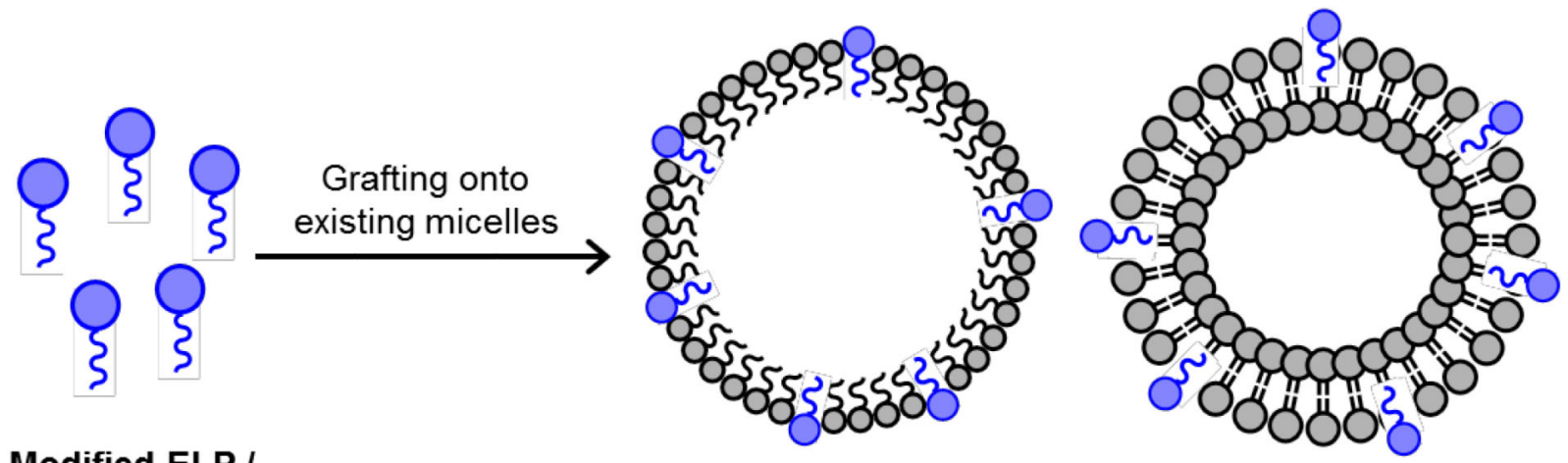

\section{Modified ELP /}

ELP-conjugate

Composite ELP-based micelles

Figure 8.

Fabrication of composite ELP-based nanoparticles. ELP-based monomer blocks composed of segments with differential hydrophobicity can undergo entropy-driven self-assembly. Alternatively, ELPs or ELP-hybrids terminally modified with a hydrocarbon tail can be adsorbed or grafted onto existing micellar constructs via hydrophobic incorporation into the liposome bilayer. 


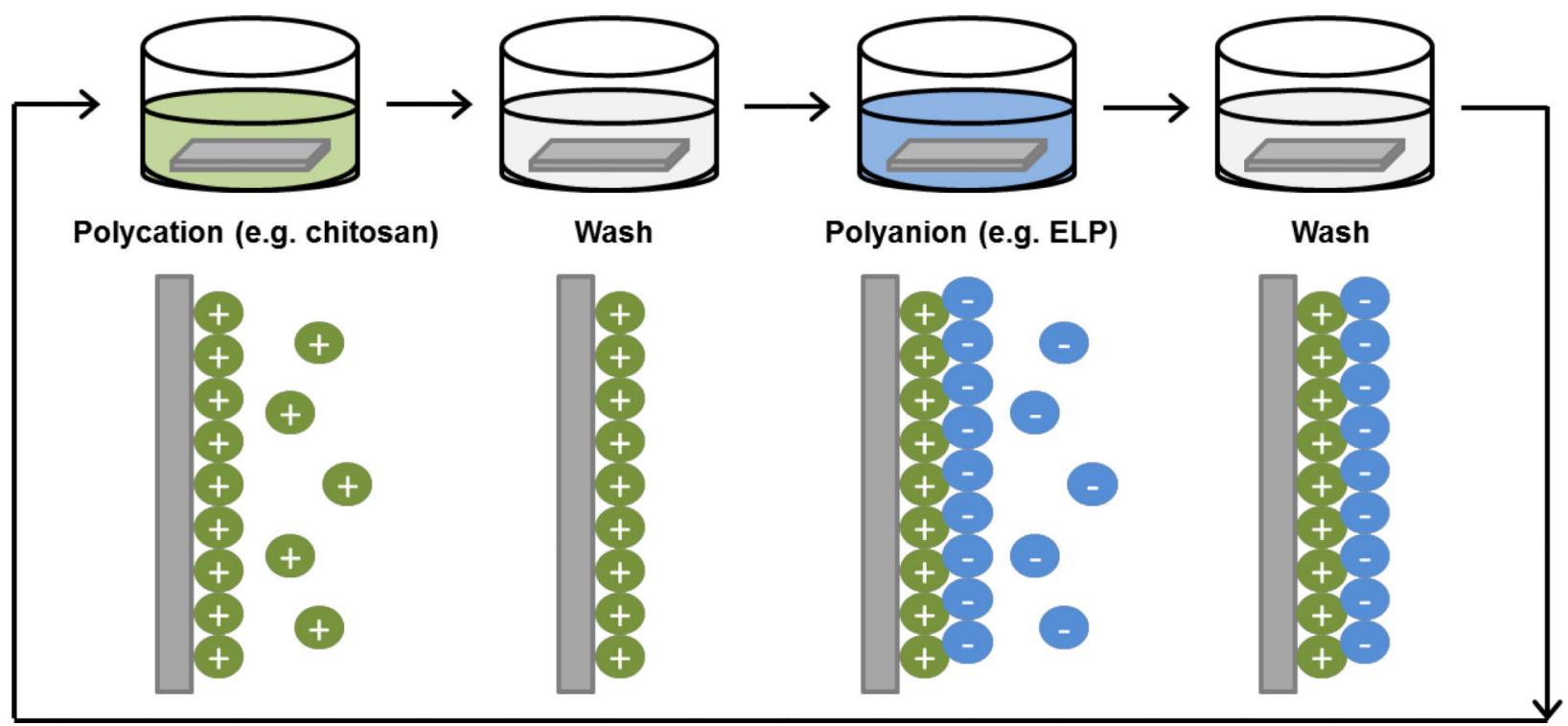

Figure 9.

ELP-based nanofilm fabrication using layer-by-layer technology. Surface charge is induced by the adsorption of charged polyelectrolytes. Electrostatic attractions between oppositelycharged layers drive the assembly of multi-lamellar materials. 


\section{Table 1}

Mechanical properties and applications of elastin-only electrospun materials.

\begin{tabular}{|l|c|c|c|c|l|l|l|}
\hline Scaffold materials & Cross-linker & Fiber diameter $(\boldsymbol{\mu m})$ & Pore size $(\boldsymbol{\mu m})$ & Tensile modulus $(\mathbf{k P a})$ & Cells cultured & Potential application/s & Reference \\
\hline Tropoelastin & GA & $1-7$ & $7-12$ & $140-220$ & Fibroblasts & $\begin{array}{l}\text { Dermal replacement; } \\
\text { wound healing }\end{array}$ & \multicolumn{1}{|c|}{$[41]$} \\
\hline Tropoelastin & HMDI & $1-3.5$ & & 111 & $\begin{array}{l}\text { Vascular } \\
\text { smooth } \\
\text { muscle cells }\end{array}$ & Vascular biomaterial & {$[29]$} \\
\hline Tropoelastin & GA & - & - & - & $\begin{array}{l}\text { Adipocyte } \\
\text { derived stem } \\
\text { cells }\end{array}$ & $\begin{array}{l}\text { Stem cell delivery } \\
\text { vehicle }\end{array}$ \\
\hline Tropoelastin & DSS & - & - & $160-240$ & $\begin{array}{l}\text { Bone marrow } \\
\text { derived } \\
\text { endothelial } \\
\text { cells }\end{array}$ & Vascular scaffold \\
\hline Tropoelastin & DSS & & & & $\begin{array}{l}\text { Bone marrow } \\
\text { derived } \\
\text { endothelial } \\
\text { cells }\end{array}$ & Vascular scaffold \\
\hline
\end{tabular}

GA: glutaraldehyde; HMDI: Hexamethyene diisocyanate; DSS: disuccinimidyl suberate 
Table 2

Mechanical properties and applications of elastin-only hydrogels.

\begin{tabular}{|c|c|c|c|c|c|c|c|}
\hline \multicolumn{2}{|c|}{ Precursor materials } & \multirow{3}{*}{$\begin{array}{c}\text { Cross-linker } \\
\begin{array}{c}\mathrm{GA}+\text { high } \\
\text { pressure } \mathrm{CO}_{2}\end{array}\end{array}$} & \multirow{2}{*}{$\begin{array}{c}\begin{array}{c}\text { Tensile / } \\
\text { compressive } \\
\text { modulus } \\
(\mathbf{k P a})\end{array} \\
11^{\mathrm{E}} ; 2^{\mathrm{C}}\end{array}$} & \multirow{2}{*}{ 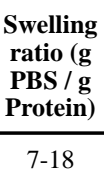 } & \multirow{2}{*}{$\begin{array}{c}\text { Cells cultured } \\
\text { Fibroblasts }\end{array}$} & \multirow{2}{*}{$\begin{array}{c}\text { Potential application/s } \\
\text { Dermal replacement }\end{array}$} & \multirow{2}{*}{$\begin{array}{c}\text { Reference } \\
{[50]}\end{array}$} \\
\hline Tropoelastin/a-elastin & $0 / 100$ & & & & & & \\
\hline & $25 / 75$ & & $14^{\mathrm{E}} ; 5^{\mathrm{C}}$ & 7 & & & \\
\hline & $50 / 50$ & & $29^{\mathrm{E}} ; 12^{\mathrm{C}}$ & $5-7$ & & & \\
\hline & $100 / 0$ & & $47^{\mathrm{E}} ; 6^{\mathrm{C}}$ & $6-8$ & & & \\
\hline \multirow[t]{3}{*}{ Tropoelastin/a-elastin } & $25 / 75$ & \multirow[t]{3}{*}{ GA } & $8^{\mathrm{E}} ; 2^{\mathrm{C}}$ & - & \multirow[t]{3}{*}{ Fibroblasts } & \multirow[t]{3}{*}{ Dermal replacement } & \multirow[t]{3}{*}[50]{} \\
\hline & $50 / 50$ & & $12^{\mathrm{E}} ; 6^{\mathrm{C}}$ & - & & & \\
\hline & $100 / 0$ & & $33^{\mathrm{E}} ; 4^{\mathrm{C}}$ & - & & & \\
\hline \multicolumn{2}{|l|}{ Tropoelastin } & BS3 & $220-280^{\mathrm{E}}$ & $4-7$ & Epithelial cells & Elastic tissue repair & [48] \\
\hline \multicolumn{2}{|l|}{ Tropoelastin } & Lysyl oxidase & $8-12^{\mathrm{E}}$ & 5.4 & - & - & [275] \\
\hline \multicolumn{2}{|l|}{ Tropoelastin } & MA & $2.8-14.8^{\mathrm{E}}$ & & $\begin{array}{c}\text { Human } \\
\text { umbilical vein } \\
\text { endothelial } \\
\text { cells }\end{array}$ & - & [42] \\
\hline \multicolumn{2}{|l|}{ a-elastin } & EGDE & $4-120^{\mathrm{E}}$ & $10-25$ & $\begin{array}{c}\text { Vascular } \\
\text { smooth muscle } \\
\text { cells }\end{array}$ & - & [276] \\
\hline \multicolumn{2}{|l|}{$a$-elastin } & $\begin{array}{l}\mathrm{HMDI}+\text { high } \\
\text { pressure } \mathrm{CO}_{2}\end{array}$ & $4-9^{C}$ & 6.8 & - & $\begin{array}{l}\text { Soft tissue repair; spinal } \\
\text { replacement }\end{array}$ & {$[54]$} \\
\hline \multicolumn{2}{|l|}{ a-elastin } & HMDI & $11-19^{\mathrm{C}}$ & 4.8 & Fibroblasts & - & [54] \\
\hline
\end{tabular}

GA: glutaraldehyde; BS3: bis(sulfosuccinimidyl)suberate; MA: Methacrylic anhydride; EGDE: ethylene glycol diglycidyl ether; HMDI: Hexamethylene diisocyanate. 


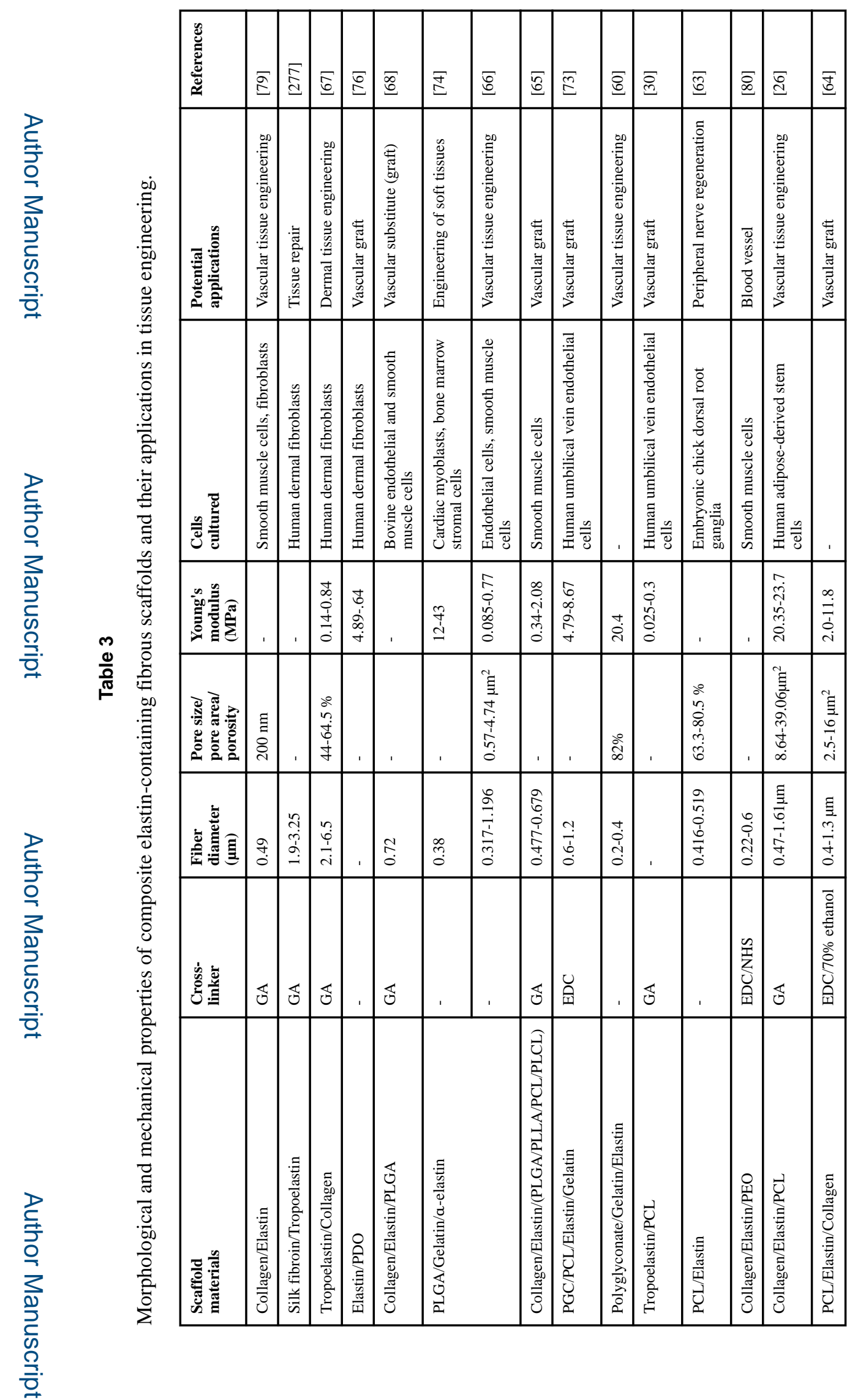

$A_{d}$ Healthc Mater. Author manuscript; available in PMC 2016 November 18. 


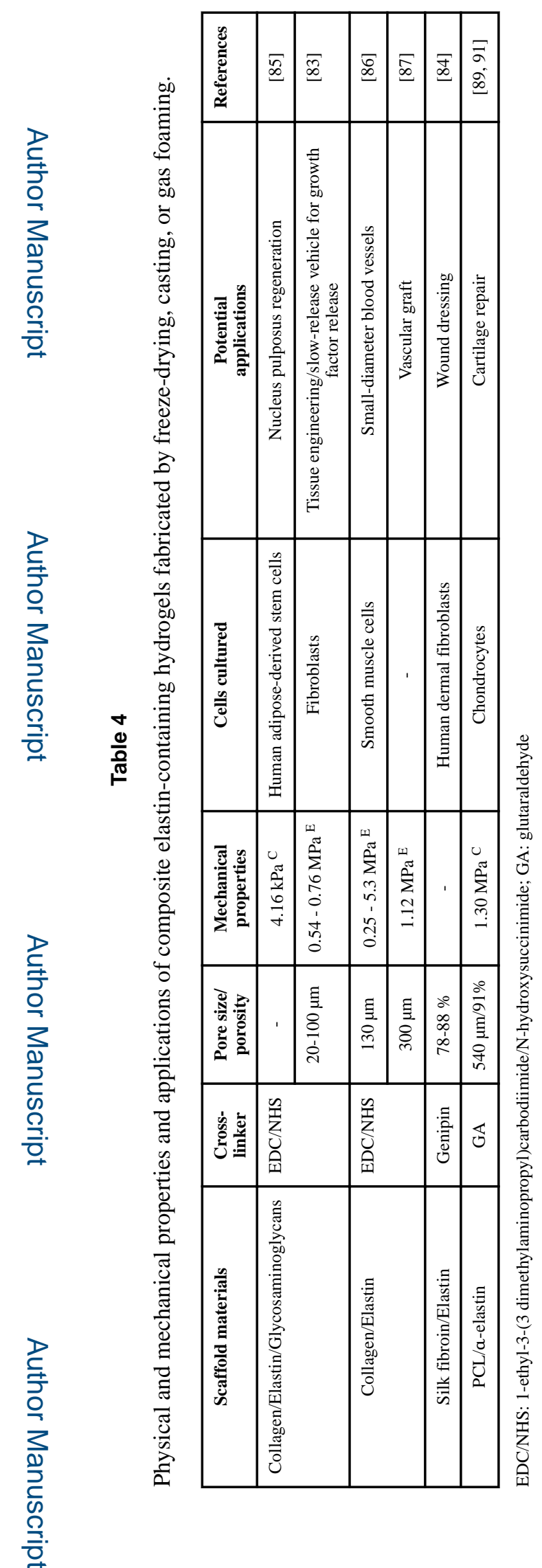

$A_{d}$ Healthc Mater. Author manuscript; available in PMC 2016 November 18. 
Table 5

Mechanical properties of ELP-based polymer networks compared to natural polymers and native tissues.

\begin{tabular}{|c|c|c|c|c|c|c|}
\hline Polymer & Cross-linker & Monomer MW (kDa) & Concentration (mg/ml) & Tensile modulus ( $\mathrm{kPa}$ ) & $\begin{array}{c}\text { Dynamic } \\
\text { shear } \\
\text { modulus } \\
(\mathrm{kPa})\end{array}$ & Reference \\
\hline ELP & None (coacervate) & 36 & 324 & - & 0.08 & [194] \\
\hline ELP & tTG & 47.1 & 100 & - & 0.26 & {$[148]$} \\
\hline ELP & DSS & 37.1 & $\mathrm{~N} / \mathrm{A}$ & $350-970$ & $120-320$ & {$[150]$} \\
\hline ELP fusion polypeptide & BS3 & 37.1 & $200-400$ & $80-700$ & $22-60$ & {$[150]$} \\
\hline ELP & TSAT & $42.7,47.1$ & 180 & - & $8-10$ & [153] \\
\hline ELP & THPP & $31,28.3$ & 200 & - & $5.8-45.8$ & {$[151]$} \\
\hline ELP fusion polypeptide & HMDI & $14-59$ & 100 & $400-930$ & - & [207] \\
\hline ELP & $\gamma$-irradiation & $15-50$ & 500 & - & $10-200$ & [146] \\
\hline ELP & Genipin & 10 & 10 & 1800 & - & [278] \\
\hline ELP & PQQ & 10 & 10 & 400 & - & [279] \\
\hline Nucleus pulposus & $\begin{array}{c}\text { Enzymatic / in } \\
\text { vivo }\end{array}$ & - & - & - & 11 & {$[280]$} \\
\hline Articular cartilage & $\begin{array}{c}\text { Enzymatic / in } \\
\text { vivo }\end{array}$ & - & - & - & 440 & [281] \\
\hline Ligament elastin & $\begin{array}{l}\text { Enzymatic / in } \\
\text { vivo }\end{array}$ & - & - & 1100 & - & [282] \\
\hline Aortic elastin & $\begin{array}{c}\text { Enzymatic / in } \\
\text { vivo }\end{array}$ & - & - & 810 & - & [283] \\
\hline
\end{tabular}

ELP, elastin-like polypeptide; tTG, tissue transglutaminase; DSS; BS3, bis(sulfosuccinimidyl) suberate; TSAT, tris-succinimidyl aminotriacetate; THPP, $\beta$-[tris(hydroxymethyl)phosphine]-propionic acid; HDMI, hexamethylene diisocynate; PQQ, pyrroloquinoline quinone. 
Table 6

Composition, form, and potential applications of composite ELP-based materials.

\begin{tabular}{|c|c|c|c|}
\hline \multicolumn{2}{|l|}{ Components } & \multirow{2}{*}{$\begin{array}{l}\text { Material } \\
\text { Hydrogel }\end{array}$} & \multirow{2}{*}{$\begin{array}{l}\text { Applications } \\
\text { Cell encapsulation }{ }^{[232]}\end{array}$} \\
\hline Elastin-like peptide & VEGF-mimetic peptide & & \\
\hline & Silk-derived peptide & Nanoparticle & Biosensors, tissue engineering, drug delivery ${ }^{[213]}$ \\
\hline & Silk-derived peptide & Fibrous mat & Tissue engineering $\left[250,{ }^{258},{ }^{270]}\right.$ \\
\hline & Fibronectin-derived motif & Membrane & Nerve conduit ${ }^{[235]}$ \\
\hline & $\begin{array}{l}\text { Growth factor (e.g. keratinocyte growth } \\
\text { factor) }\end{array}$ & Nanoparticle & Drug delivery $[216]$ \\
\hline & Cytokine (e.g. interleukin-10) & Nanoparticle & Drug delivery ${ }^{[221]}$ \\
\hline & Silk & Hydrogel & ECM-mimetic scaffold ${ }^{[250]}$ \\
\hline & Silk & Film/sheet & $\begin{array}{l}\text { Ophthalmic drug delivery } \\
\text { Wound dressing }\end{array}$ \\
\hline & Collagen & Hydrogel & $\begin{array}{l}\text { Drug delivery }{ }^{[237]} \\
\text { Human oral mucosa scaffold }{ }^{[248]} \\
\text { Soft tissue replacement }{ }^{[242]} \\
\text { Bone repair }{ }^{[236},{ }^{246]} \\
\text { Selective tissue culture substrate }{ }^{[233]}\end{array}$ \\
\hline & Collagen & Sheet & $\begin{array}{l}\text { Soft tissue repair }{ }^{[265]} \\
\text { Abdominal wall replacement }{ }^{[265]}\end{array}$ \\
\hline & Collagen and fibronectin & Tubular sheet & Vascular graft ${ }^{[269]}$ \\
\hline & Fibrinogen and thrombin & Hydrogel & Tympanic membrane replacement ${ }^{[238]}$ \\
\hline & Fibronectin & Hydrogel & Tissue scaffold ${ }^{[240]}$ \\
\hline & Hyaluronan & Injectable hydrogel & Intervertebral disc mimetic scaffold $\left[244,{ }^{252]}\right.$ \\
\hline & Chitosan & Nanofilm & Biodegradable smart coatings ${ }^{[266]}$ \\
\hline & Polysaccharides & Nanofilm & Tissue engineering; drug delivery ${ }^{[267]}$ \\
\hline & $\begin{array}{l}\text { Bioglass, carbon nanosphere chains, } \\
\text { collagen }\end{array}$ & Hydrogel & Bone tissue scaffold ${ }^{[245]}$ \\
\hline & Calcium phosphate & Injectable cement & Bone filling and dental implant ${ }^{[253]}$ \\
\hline & Statherin derivative & Hydrogel & Biomineralizing scaffold ${ }^{[241]}$ \\
\hline & Antibiotic (e.g. rapamycin) & Sheet & Drug delivery ${ }^{[234]}$ \\
\hline & Chemotherapeutic drug (e.g. doxorubicin) & Nanoparticle & Drug delivery ${ }^{[215]}$ \\
\hline & Polyethylene glycol & Nanoparticle & Drug delivery ${ }^{[214]}$ \\
\hline & Polyethylene glycol & Hydrogel & Cell encapsulation ${ }^{[239]}$ \\
\hline & Polyurethane & Electrospun scaffold & Vascular smooth muscle cell culture ${ }^{[249]}$ \\
\hline
\end{tabular}

